\title{
Geographic distances and ocean currents influence Caribbean Acropora palmata population connectivity in the Lesser Antilles
}

\author{
Japaud Aurélien 1, 2, Bouchon Claude ${ }^{1}$, Magalon Hélène ${ }^{3}$, Fauvelot Cécile 2, 4, 5, *
}

\begin{abstract}
1 UMR 7208 BOREA, Laboratoire d'excellence-CORAIL, Université des AntillesPointe-à-Pitre, Guadeloupe

2 UMR ENTROPIE (IRD, Université de La Réunion, CNRS), Laboratoire d'excellence-CORAIL, IRD de NouméaNouméa cedex, New Caledonia

3 UMR ENTROPIE (Université de La Réunion, IRD, CNRS), Laboratoire d'excellence-CORAIL, Faculté des Sciences et TechnologiesSt Denis Cedex 09, La Réunion, France

4 Université Côte d'Azur, CNRS, FRE 3729 ECOMERSNice, France

${ }^{5}$ Sorbonne Université, CNRSVillefranche-sur-Mer, France
\end{abstract}

* Corresponding author : Aurélien Japaud, email address : cecile.fauvelot@ird.fr

\begin{abstract}
:
The critically endangered coral species Acropora palmata used to dominate shallow Caribbean reefs but since the early 1980 s, populations have dramatically declined. At the Caribbean scale, A. palmata is divided into two genetically divergent lineages and most of previous works investigating population connectivity among populations involved the western lineage (in Florida, the Bahamas, the Mesoamerican Reef System, and the Greater Antilles). Small scale genetic connectivity among A. palmata populations was globally found, possibly enhancing populations' recovery at the local scale. Yet, little is known regarding the genetic connectivity of populations of the eastern lineage, especially those of the Lesser Antilles, a fragmented archipelago located at the edge of the species distribution. Here, we filled this gap by investigating the genetic diversity, population structure and connectivity of $A$. palmata populations among 36 sampled sites from 11 islands of the Lesser Antilles using 14 hypervariable microsatellite loci. Globally, genetic diversity levels in A. palmata populations from the Lesser Antilles were lower compared to what was previously reported within the Wider Caribbean. The analysis of the genetic structure, crossed with spatial autocorrelation analysis, revealed an isolation-by-distance pattern at both reef and Lesser Antilles scales. A gene dispersal distance of less than a kilometer, and a northward gene flow direction, in agreement with ocean surface currents in the region were found. Altogether, our results suggest a restricted population connectivity and short distance dispersal of A. palmata larvae within the Lesser Antilles further limited by geographic distances among suitable habitat patches. Additionally, our results suggest that southernmost populations are potential sources of larvae for the most northerly islands and have a key role in reseeding A. palmata populations of the Lesser Antilles.
\end{abstract}


Keywords : Acropora, Lesser Antilles, Larval dispersal, connectivity, Genetic diversity, Isolation-bydistance 
50 We thank Sébastien Cordonnier, Jean-Loup Manceau, Julien Lequellec, Didier Laplace and

51 Emmanuel Badias for assistance on the field. We further thank the staff of the "Parc National de

52 la Guadeloupe", the "Réserve Naturelle des îlots de Petite-Terre", the "Réserve Naturelle

53 Nationale de Saint Barthélemy", the "Réserve Naturelle Nationale de Saint-Martin", the crew of

54 the RV ANTEA during PACOTILLES campaign (http://dx.doi.org/10.17600/15005200),

55 Christophe Menkès for providing the ocean current map and Simon Van Wynsberge for

56 geographic distance estimations with barriers. We sincerely thank two anonymous reviewers for 
57 their valuable comments and suggestions on previous versions of the manuscript. This project

58 was co-funded by the Laboratoire d'Excellence CORAIL (Agence nationale de la recherche,

59 France) and the Agence des Aires Marine Protégées (France). 


\section{Introduction}

Branching corals of the Acroporidae family present an important role, in building and structuring world's coral reef ecosystems (Bruckner 2002). More than one hundred Acropora species have been identified in the Indo-Pacific region (Wallace 1999; Veron 2000), but only two species are described in the Caribbean region, the elkhorn coral A. palmata (Lamarck, 1816) and the staghorn coral A. cervicornis (Lamarck, 1816), with A. prolifera (Lamarck, 1816), being a first-generation hybrid of the two former species (van Oppen et al. 2000; Vollmer and Palumbi 2002), and not a hybrid species (Willis et al. 2006). In the past, A. palmata and A. cervicornis formed dense, monospecific and high-structural thickets in the Caribbean coral reefs, from shallow to intermediate depth (0.5-6 $\mathrm{m}$ and 7-15 $\mathrm{m}$ depth for A. palmata and A. cervicornis respectively; Goreau 1959; Bak 1975) . However, in the late 1970s and 1980s, their populations have declined dramatically, mostly due to the combined effects of "white band" disease, hurricanes, and other human-related factors (Precht et al. 2002; Williams and Miller 2005; Miller et al. 2009), to the point that Caribbean endemic Acropora species have been classified as 'critically endangered' since 2008 by the International Union for Conservation of Nature (IUCN), regulated by the US Endangered Species Act and listed on the Washington Convention (CITES, Appendix II; Aronson et al. 2008; Carpenter et al. 2008).

The decline of A. palmata and A. cervicornis populations has led the scientific community to follow their possible recovery by investigating the genetic structure and dynamics of these populations since the early 2000's. Indeed, molecular genetic approaches are one of the tools that can improve the conservation and management objectives in the marine realm (von der Heyden et al. 2014). In particular, the theoretical framework of population genetics offers the possibility to infer population connectivity in marine species and estimate the spatial extent of larval dispersal in marine organisms, above all for sessile organisms showing a dispersal phase through propagules. Identifying sources of propagules to be protected are critical needs for managers who are increasingly operating under the implicit assumption that climate change and other human-related disturbances are unlikely to improve in the short term. 
Population connectivity is a force which maintains the genetic cohesion of a biological species over its distribution range (Mayr 1963). It represents the transfer of individuals among populations, which can if successful (i.e. the established individuals participate to the reproduction event) lead to a transfer of alleles among populations. In sessile marine organisms, this connectivity is insured by reproductive outputs, from the gametes up to competent larvae ready to settle. Genetic connectivity is the main process by which populations maintain their genetic diversity levels and homogenize their genetic variation. Indeed, classic island models of population genetics (Wright 1940) invoke gene flow (from migration) and genetic drift as the two main processes regulating genetic diversity (selection and mutation being comparatively negligible). For example, small habitat patches theoretically contain small populations so that alleles are expected to be lost due to the effect of genetic drift. Only immigration may counter this effect on a short time scale by introducing alleles (either already present or new ones). Maintaining high genetic diversity levels is particularly crucial for the subsistence of populations in highly variable environments or those subject to rapid anthropogenic changes (Miller and Ayre 2004; Reusch et al. 2005; Yeoh and Dai 2009). Indeed, genetic diversity can affect species productivity, population growth and stability, as well as inter-specific interactions within communities, and ecosystem-level processes (Hughes et al. 2008). In addition to migration and genetic drift, the mode of reproduction (sexual or asexual) also affect the levels of population genetic diversity, above all in populations with known high clonal propagation. Indeed, asexual reproduction (or clonal reproduction) by fragmentation is an important propagation mode for branching corals with high growth rates (Highsmith 1982). Fragmentation allows the installation of a new structural coral colony on a reef by settlement of a coral fragment issued from a mother-colony already set up on the same reef. The new colony and the maternal colony are genetically identical, members of the same clone (or genet), despite being two distinct ramets. Mature coral colonies issued from clonal propagation and sharing the same genotype (i.e. forming a genet) therefore see their sexual reproductive output increased as compared to colonies represented by only one physical individual (Coffroth and Lasker 1998). Additionally, clonal reproduction counteracts high larval and juvenile mortality rates often 
linked with sexual reproduction. However, because of the limited dispersal capacity of asexual reproduction and because species with dual reproduction tend to form multiclonal populations, the greatest genetic impact of clonality occurs at fine spatial scales within populations (VallejoMarín et al. 2010). Indeed, the greater the number of genetically identical ramets (i.e. clone mates), the smaller the effective population size relative to the apparent census population size. Consequently, genetic diversity and population viability can be significantly overestimated in census counts without knowledge of clonal extent (Rossetto et al. 2004). The consequences of a high clonal rate can therefore be dramatic, with a low genetic diversity within isolated populations and a possible increase of the associated dangers to stress events for potentially badly-adapted genets to new environmental conditions (Reusch et al. 2005). Long term effects of clonal reproduction depend on the balance between costs and benefits of this process (Lirman 2000). In this context, assessing the clonal propagation and genetic diversity levels in populations of endangered species is of primary importance.

The elkhorn coral A. palmata, as many other coral species, is known to reproduce both sexually and asexually, through fragmentation (Highsmith 1982). Because (1) sexual reproduction occurs only once a year, through the synchronized release of gametes in the water column (generally after the August full moon, Szmant 1986; Miller et al. 2016) and (2) pelagic larvae can settle from 5 days up to a maximum of 20 days after fertilization in conditions not propitious to earlier larval recruitment (Baums et al. 2005b), larval dispersal, in terms of distance and frequency, and genetic connectivity of this species are expected to be limited. Previous genetic studies on A. palmata Caribbean populations, both in terms of geographical variation of its clonal structure and spatial genetic structuring, have mainly been conducted along the reefs of the Gulf of Mexico (Florida, Baums et al. 2005a, b, 2006a), the Bahamas (Baums et al. 2005b, 2006a; Garcia Reyes and Schizas 2010; Mège et al. 2015) the Greater Antilles (Puerto Rico and US Virgin Islands, Baums et al. 2005b, 2006a; Garcia Reyes and Schizas 2010; Mège et al. 2015), the Mesoamerican Reef System (MRS, Baums et al. 2005b, 2006a; Porto-Hannes et al. 2015) and the islands off the Venezuelan coast (Los Roques National Park and the Netherlands islands of Curaçao and Bonaire, Baums et al. 2005b, 2006a; Zubillaga et al. 2008; Porto-Hannes et al. 2015; Mège et al. 
2015). Over all, investigation on the population genetic structure of A. palmata in the Caribbean revealed a main phylogeographic split dividing $A$. palmata populations into two genetically divergent lineages, eastern and western, with the northern genetic break being located around the Eastern Puerto Rican region (Baums et al. 2005b, 2006a, b; Mège et al. 2015) and the southern being located somewhere between Panama and Curaçao (Baums et al. 2005b; PortoHannes et al. 2015). Within the western lineage, at a rather small scale (< ca. $500 \mathrm{~km})$, genetic differentiation among sampling locations seemed to be weak and not related to geographic distances (Baums et al. 2005b; Porto-Hannes et al. 2015; Mège et al. 2015). Isolation-by-distance (IBD) patterns were observed 1) in the admixture region of Puerto Rico, partially explained by the mix of the two genetically divergent A. palmata eastern and western lineages (Mège et al. 2015) and 2) at large spatial scales involving inter-lineages comparisons (Porto-Hannes et al. 2015; Mège et al. 2015). So far, only two studies reported significant genetic structuring within the eastern lineage, though only two to three distant (shortest nautical distance $<600 \mathrm{~km}$ ) sampling locations were involved in both cases (US Virgin Islands vs. Saint-Vincent and the Grenadines vs. Curaçao and Bonnaire in Baums et al. 2005b; Guadeloupe vs. Curaçao in Mège et al. 2015).

Across the Caribbean, A. palmata populations were found to be mostly self-recruiting, with sexual recruitment being more prevalent in the eastern lineage than in the western one $[\underline{B} \underline{\operatorname{Ba}} \underline{\underline{u}} \underline{\underline{m}}$. et al. 2005_ 2006]. Nevertheless, the contribution of both reproductive modes to population structure was found to be unrelated to a purely geographic division between distinct genetic lineages (Baums et al. 2006a; Porto-Hannes et al. 2015; Mège et al. 2015). Also, it seems that asexual reproduction by fragmentation in $A$. palmata populations is more likely explained by differences among reefs in habitat characteristics and related environmental conditions (e.g. reef orientation and inclination, current dynamics, competition for space with other reef organisms...) than by differences between lineages (Baums et al. 2006a; Porto-Hannes et al. 2015; Mège et al. 2015).

As previously mentioned, most of these genetic works conducted on A. palmata populations involved the western lineage and only few populations from the eastern lineage were studied. 
171 This eastern lineage is mainly characterized by populations from the Lesser Antilles, an arc of 172 islands from $18^{\circ} \mathrm{N}$ to $11^{\circ} \mathrm{N}$ and $59^{\circ} \mathrm{W}$ to $70^{\circ} \mathrm{W}$, part of the Eastern Caribbean ecoregion (Spalding 173 et al. 2007), much less studied than the Western Caribbean ecoregion. While most conservation 174 efforts in the Lesser Antilles have been conducted so far on the terrestrial fauna (birds,

175 herpetofauna, insects, etc) and flora because of high rates of endemism in islands (e.g. FranciscoOrtega et al. 2007; Hedges and Díaz 2011; Latta 2012), conservation strategies regarding marine species are rising in response to increasing damages observed on coral reef ecosystems (see for example, Young et al. 2012).

In this context, estimating genetic diversity and connectivity of A. palmata populations in the Lesser Antilles archipelago is needed to provide information regarding the extent over which source reefs can eventually rescue damaged reefs through input of coral larvae, in order to improve management, protection and conservation of this endangered species. Thus, the main objectives of this study were (1) to estimate the levels of genetic diversity of A.palmata populations of the Lesser Antilles and compare them to those of already studied Caribbean populations, (2) to investigate A. palmata spatial scales of larval dispersal in the Lesser Antilles, and (3) to explore the possible contributing factors explaining the observed genetic differences among A. palmata populations in this region. To do so, A. palmata colonies were sampled in 36 study sites from 11 islands of the Lesser Antilles, in a hierarchical framework. Fourteen hypervariable microsatellite loci were used, first to determine the number of genotypes among the sampled colonies in order to estimate the genetic diversity and clonality, and secondly, to assess the population genetic structure and the connectivity level among A. palmata populations of the Lesser Antilles.

\section{Materials and methods}

\section{Sampling}

A total of 1,042 colonies of Acropora palmata were sampled in 36 localities from 11 islands from the Lesser Antilles, from the northern islands of St. Martin and St. Barthélemy to the southernmost islands of St. Vincent and the Grenadines (Table 1, Figure 1), covering a latitudinal 
transect of ca. $600 \mathrm{~km}$. Most of these islands are volcanic, mountainous and present fringing reefs subject to considerable terrigenous inputs from erosion (Bouchon et al. 2008). Most A. palmata colonies $(\mathrm{n}=642)$ sampled from sites coded from PAC01 to PAC28 were collected in April and May 2015 during "PACOTILLES” campaign on board RV ANTEA (IRD). Other colonies from Guadeloupe ( $n=353)$ and St. Barthélemy $(n=47)$ were collected between May 2011 and October 2014 during specific field trips. Fragments of colonies (tip of branch) were collected by snorkeling, between 1 and $5 \mathrm{~m}$ depth. For the site Caye à Dupont (Guadeloupe), 80 colonies were sampled exhaustively in a $30 \mathrm{~m}$ radius circle (see Japaud et al. 2015). For all the other sites, colonies were sampled along an imaginary transect following the coastline until ca. 50 colonies per site were reached (usually between 2 and 3 hours), though avoiding small but thick colonies nearby $(<1 \mathrm{~m})$ large colonies (that may correspond to the breakage of branches of the large colonies and their subsequent re-attachment). Sampled colonies were photographed underwater for most of the sites $(n=15 / 21)$ of the PACOTILLES campaign and snipped fragments placed in individually labeled zip bag, numbered along each transect. After sampling, coral fragments were transferred into Falcon tubes containing 70\% ethanol and stored at room temperature until processing.

\section{Molecular analyses}

Total genomic DNA was extracted from 5-10 polyps per fragment, using a DNA Purification Kit (formerly Gentra Puregene, Qiagen, Valencia, CA, USA) following the manufacturer's protocol. Fourteen A. palmata specific microsatellite loci (Baums et al. 2005a, 2009) were PCR amplified following the protocol described in (Japaud et al. 2015). Amplified fragments were sent to the GENTYANE platform (INRA, Clermont-Ferrand, France), where they were resolved on an ABI 3730XL sequencer with a GeneScan LIZ-500 internal size standard (Applied Biosystems). Alleles were sized using GENEMAPPER v. 4.0 (Applied Biosystems). We used GMCONVERT (Faircloth 2006) to convert the exported GENEMAPPER table of genotypes.

\section{Data analyses}

Our dataset was tested for scoring errors and null alleles using MICRO-CHECKER v. 2.2.3 (van Oosterhout et al. 2004). All distinct multilocus genotypes (MLGs) and clones were distinguished 
among colonies using GENALEX v. 6.502 (Peakall and Smouse 2006, 2012). Associated probabilities of identity $(P I)$ were further estimated in order to assess the probability that two different sampled colonies present an identical MLG just by chance given our set of 14 microsatellite markers.

Since A. prolifera colonies could be present within our sampling [i.e. hybrids between A. palmata and A. cervicornis may present an A. palmata morphology (Acropora Biological Review Team 2005)], we performed a discriminant analysis using STRUCTURE v. 2.3.4 (Pritchard et al. 2000). For this, we added to our A. palmata MLGs obtained from the analysis of 1,042 colonies some reference MLGs of $A$. cervicornis $(\mathrm{n}=25)$ and A. prolifera $(\mathrm{n}=7)$, which had been previously genotyped (with the exact same set of loci) (Japaud et al. 2014, 2015). By fixing K=2, we enforced colonies to belong either to an A. palmata cluster, or to an A. cervicornis cluster (in this case, known A. prolifera are expected to present intermediate percentages of membership to each cluster). Percentage of membership of each sampled colony to each cluster were obtained pooling the results of 10 independent runs with CLUMPP v. 1.1.2 (Jakobsson and Rosenberg 2007), after running STRUCTURE $\left(5 \times 10^{4}\right.$ iterations, burn-in $\left.=5 \times 10^{3}\right)$ under an admixture ancestry model, using species information as LOCPRIOR (A. palmata, A. cervicornis, or A. prolifera based on morphology) and assuming correlated allele frequencies. Additionally, a correspondence analysis was performed over all these genotypes with GENETIX v.4.05.2 (Belkhir et al. 2004), in order to illustrate and confirm the clustering analysis.

Genotypic richness, genotypic diversity and genotypic evenness were estimated to evaluate the part of clonality (asexual reproduction) for each site. Genotypic richness $\left(N_{g} / N\right)$ was calculated as the number of unique identified MLGs $\left(N_{g}\right)$ over the total number of sampled colonies $(N)$. Genotypic richness ranges from nearly 0 to 1 : the closer to 1 , the higher the number of MLGs and, thus, the smaller the number of clones. Genotypic diversity $\left(G_{O} / G_{E}\right)$ was estimated as the observed genotypic diversity ( $G_{0}$; Stoddart and Taylor 1988) over the expected genotypic diversity $\left(G_{E}\right)$ to access the relative importance of sexual reproduction in a population. Observed genotypic diversity was calculated as: 


$$
G_{O}=\frac{1}{\sum_{i}^{k} g_{i}^{2}}
$$

where $g_{i}$ is the relative frequency of the $i^{\text {th }}$ of $k$ MLGs. As expected for a full sexually reproducing population, expected genotypic diversity $\left(G_{E}\right)$ equals the total number of sampled and analyzed colonies $(N)$. Genotypic evenness $\left(G_{O} / N_{g}\right.$; Coffroth and Lasker 1998$)$ was estimated as the ratio between the observed genotypic diversity $\left(G_{0}\right)$ and the number of unique identified MLGs $\left(N_{g}\right)$. Genotypic evenness measures the distribution of genotype abundances: a population with equally abundant genotypes yields a value equal to 1 while a population dominated by a single genotype gives a value close to 0 . For populations presenting only one genotype, genotypic evenness has no meaning and is equal to 1 . Based on the combination of genotypic diversity $\left(G_{O} / G_{E}\right)$ and genotypic evenness $\left(G_{O} / N_{g}\right)$, sites were classified into four categories to facilitate discussion (Baums et al. 2006a): asexual, mostly asexual, mostly sexual and sexual. Clustering among groups was realized in R using the 'kmeans' function of the R 'Stats' package (R Core Team 2016). All subsequent analyses were conducted keeping only one representative per MLG and per sampling site.

Null allele frequencies $(r)$ were estimated for each locus and within each sampling site using the expectation maximization algorithm (Dempster et al. 1977) implemented in FREENA (Chapuis and Estoup 2007). Genotypic linkage disequilibria, fixation index estimates ( $F_{I S}$; Weir and Cockerham 1984) and significant departures from Hardy-Weinberg equilibrium were estimated and tested using the exact tests implemented in the online GENEPOP v. 4.2 (Raymond and Rousset 1995) with default Markov Chain parameters. Observed heterozygosity $\left(H_{0}\right)$ and unbiased expected heterozygosity $\left(H_{E}\right)$ were estimated with GENALEX v. 6.502 (Peakall and Smouse 2006, 2012). Allelic richness (rarefied or extrapolated for $\mathrm{N}=50$ with $95 \%$ confidence bounds) was estimated within each sampling site using the 'ARES' package in R (van Loon et al. 2007; R Core Team 2016) and for island estimates, allelic richness was averaged over sample sites. Genetic differentiation among populations was estimated i) using Weir and Cockerham's (1984) estimator $\theta$ in GENEPOP and ii) using Weir's (1996) unbiased $F_{\mathrm{ST}}$ estimated using the ENA method in FREENA (Chapuis and Estoup 2007) with correction for null alleles and the 
significance of the test $\left(\mathrm{H}_{0}: F_{\mathrm{ST}}=0\right)$ assessed using the $95 \%$ confidence interval obtained through bootstrap resampling over loci in FREENA. An analysis of molecular variance (AMOVA) (Excoffier et al. 1992) implemented in ARLEQUIN version 3.5.2 (Excoffier and Lischer 2010) was conducted based on Weir and Cockerham's (1984) $F_{\mathrm{ST}}$ estimates to examine the partition of the genetic variance among A. palmata samples in the Lesser Antilles. With this purpose the 34 samples were grouped according to their island of origin with two exceptions: Les Saintes sample was grouped together with Guadeloupe samples, and Union Island sample was grouped together with Bequia samples.

Genetic structuring was further investigated using a Bayesian clustering approach to estimate the most likely number of clusters $(K)$ among all MLGs using STRUCTURE v. 2.3.4 (Pritchard et al. 2000). Log-likelihood values for each $K$ (number of inferred populations: 1-37) were computed by running an admixture ancestry model with no location prior and assuming correlated allele frequencies ( 5 replicates, $5 \times 10^{5}$ iterations, burn-in $=2 \times 10^{3}$ ). Following the recommendations of Evanno et al. (2005), the ad hoc statistic $\Delta K$ was calculated using STRUCTURE Harvester (Earl and VonHoldt 2012). Similarities or dissimilarities among island populations were further visualized through a principal coordinates analysis (PCoA) using the "covariance-standardized" PCoA method in GENALEX v. 6.502 (Peakall and Smouse 2006, 2012) and based on a pairwise genetic distance matrix using the "codom-genotypic" option. To specifically test for isolation-by-distance (IBD) pattern. (Mantel 1967) tests were performed in R with the function 'mantel.rtest' of the package 'ade4', with $10^{4}$ permutations of the corrected pairwise $\left(F_{\mathrm{ST}} /\left(1-F_{\mathrm{ST}}\right)\right)$ matrix estimated in FREENA among sites and islands, and the geographic distance matrix. For geographic distance estimates, we used the shortest distance among sites considering islands as barriers to larval dispersal estimated using the 'costDistance' function of the package 'gdistance' in R (van Etten 2015; R Core Team 2016). Geographic distances for each pair of islands were estimated using the center of each island as a landmark.

To visualize the fine-scale spatial genetic structure of Acropora palmata and estimate gene dispersal distance throughout the islands of the Lesser Antilles in the context of IBD, we 
estimated the genetic similarity between every pair of individuals $i$ and $j$ with Loiselle's kinship coefficient ( $F_{\mathrm{ij}}$, Loiselle et al. 1995) and regressed the obtained values on the spatial distance between individuals and its natural logarithm in a spatial autocorrelogram, in SPAGEDI v. 1.5 (Hardy and Vekemans 1999, 2002). Loiselle's kinship coefficient was estimated among colonies organized in 10 automatically defined spatial distance intervals to reach an even number of pairwise comparisons within each interval. The significance of kinship among individuals within each distance interval was obtained using $10^{4}$ permutations.

Wright's neighborhood size was further estimated as $N b \approx-\left(1-F_{\mathrm{N}}\right) / b_{\mathrm{Ld}}$ where $b_{\mathrm{Ld}}$ is the regression slope of pairwise values on the logarithm of spatial distance, and $F_{\mathrm{N}}$ is the kinship coefficient estimated between adjacent individuals. Because this relationship holds best when the regression is computed within short geographic distances (Rousset 2000), assuming a twodimensional population at drift-dispersal equilibrium, $F_{\mathrm{N}}$ et $b_{\mathrm{Ld}}$ were estimated using an iterative procedure described in SPAGEDI by regressing pairwise kinship coefficients on $\ln$ (distance) over a restricted distance range (set to $0-30 \mathrm{~km}$, based on significant kinship coefficient estimates within distance intervals and the average geographic distance between sites located on the same island). The mean-squared distance of gene dispersal, $\sigma$, was then inferred in SPAGEDI from the neighborhood size as $N b$ is related to $\sigma$ as follows: $N b \approx 4 \pi D e \sigma^{2}$, where $D e$ is the effective density (Rousset 2000; Vekemans and Hardy 2004) which can be approximated as $D . \mathrm{Ne} / \mathrm{N}$ where $\mathrm{Ne} / \mathrm{N}$ is the ratio of the effective to the census population sizes. There are no estimates of this ratio in A. palmata available in the literature. Yet, the fertilization potential of A. palmata is likely limited by the fact that 1 ) this species is a simultaneous hermaphrodite that release gametes (viable only few hours) in the water column once a year, in late summer (Fogarty et al. 2012; Miller et al. 2016a), 2) A. palmata is genotypically depauperate in some areas of its range (see for example Baums et al. 2006; Japaud et al. 2015 among others) and 3) different genotypes do not participate synchronically to the reproduction event, nor systematically every year (Miller et al. 2016a). Therefore, we used 0.1 and 0.01 as arbitrary upper and lower estimates for $\mathrm{Ne} / \mathrm{N}$, and $D$, A. palmata density, based on observed estimates across various reefs available in the literature (see results). 
Finally, an eventual directional gene flow in A. palmata along the Lesser Antilles was tested. Since islands of the Lesser Antilles are approximately distributed along a North-South axis, it was tested whether gene flow was oriented southward or northward. To do so, the relative directional migration coefficient among islands based on the Jost's D index $\left(D_{M}\right)$ was estimated using the online application DIVMIGRATE $\left(5 \times 10^{3}\right.$ bootstraps, $\alpha=0.05$; Jost 2008 ; Sundqvist et al. 2016). Two $D_{M}$ were estimated between each pair of island populations, representing both directions: from island $\mathrm{A}$ to island $\mathrm{B}$ and vice versa.

\section{Results}

\section{Species identification}

Among the 1,042 A. palmata colonies analysed, a total of 726 distinct MLGs were identified. From these, 96 (13\%) were represented by at least two colonies while the rest (87\%) by only one colony. The estimated probability that two genetically different colonies have identical MLG by chance using the 14 microsatellite loci $(P I)$ was $9.9 \times 10^{-15}$. Therefore, colonies harboring the same MLG were interpreted as biological clones.

The clustering analysis conducted over all the 758 MLGs (726 A. palmata, 25 A. cervicornis and seven A. prolifera) with STRUCTURE revealed that all seven known A. prolifera individuals had a maximum likelihood of membership of $70.9 \%$ to A. palmata cluster (Online Resource 1). We therefore applied a minimum threshold of $70.9 \%$ of membership to A. palmata cluster. Out of the 726 A. palmata MLGs, five were identified as belonging to possible hybrids (with likely membership to A. palmata cluster varying between 14.5 and $66.5 \%$; Online Resource 1; Figure 2) and were therefore excluded from the dataset. For more safety, three additional colonies were also excluded because of their close proximity to A. prolifera MLGs on the correspondence analysis (Figure 2), even though their membership to A. palmata cluster varied between 99 and $100 \%$. Therefore, a total of eight MLGs corresponding to eight colonies a posteriori identified as possible hybrids were excluded from the A. palmata dataset. Noteworthy, these colonies for which we had underwater pictures taken during sampling all had an A. palmata morph. 


\section{Genotypic diversity and clonality}

Genotypic richness $\left(N_{g} / N\right)$ and genotypic diversity $\left(G_{O} / G_{E}\right)$ ranged from nearly 0 for FjL (Guadeloupe) and PAC09 (Saint-Vincent) (i.e., for each site, only one MLG was found over all the colonies sampled) to 1 in PAC23 (Saint-Martin), PAC27 (Saba), AL and AM (Guadeloupe), PAC04 and PAC06 (Martinique) and PAC11 in Bequia (i.e., each sampled colony presented a distinct MLG) (Table 1). Mean genotypic richness per site $( \pm$ standard error) was $0.75 \pm 0.04(n=35)$ and mean genotypic diversity per site was $0.64 \pm 0.05(n=35)$. The smallest genotypic evenness $\left(G_{o} / N_{g}\right)$ was found in PAC15 (Saint Lucia) (0.21) where 17 MLGs were found but one of them represented $50 \%$ of the 42 sampled colonies. The highest genotypic evenness was maximal $\left(G_{o} / N_{g}=1\right)$ for the seven sites where all sampled colonies presented distinct MLGs (PAC23, PAC27, AL, AM, PAC04, PAC06 and PAC11), as well as for the two sites where a single MLG was found (FjL and PAC09), though not informative. Mean genotypic evenness per site calculated without these two latter sites was $0.79 \pm 0.04(n=33)$.

Based on the combination of genotypic diversity $\left(G_{o} / G_{E}\right)$ and genotypic evenness $\left(G_{o} / N_{g}\right)$, A. palmata stands (corresponding to each sampling site) were classified into four categories (Table 1, Figure 3): asexual, mostly asexual, mostly sexual and sexual (Baums et al. 2006b). The 'asexual' category gathered the two sites with a single MLG per site, FjL and PAC09. The 'mostly asexual' category included four sites characterized by very low values of genotypic diversity and genotypic evenness (ranged from 0.04 to 0.28 and from 0.21 to 0.49 respectively): SB1, PAC03, PAC10 and PAC15. The 'mostly sexual' category was composed by 14 sites with moderate values of genotypic diversity and genotypic evenness (from 0.33 to 0.72 and from 0.57 to 0.89 respectively): SB3, SB4, PAC21, PAC22, PAC28, LM, PC, PT, TA, PAC01, PAC02, PAC17, PAC12 and PAC13. The 'sexual' category consisted of 15 sites with the highest values of genotypic diversity and genotypic evenness ( $>0.78$ and $>0.90$ respectively): PAC23, PAC24, PAC25, PAC27, PAC20, AL, AM, FjPE, IG, IP, Lz, PAC04, PAC06, PAC08, PAC11 (Figure 3).

When looking at estimated indices per island, the number of distinct MLGs found ranged from 30 (in Saint Lucia, $\mathrm{N}=60$ ) to 256 (in Guadeloupe, $\mathrm{N}=395)$ ). Mean genotypic richness $\left(N_{g} / N\right)$ per island ranged from $0.41 \pm 0.25(\mathrm{n}=3$, Saint Vincent) to 1 for Saba with a single sampling site and 
393

394

395

396

397

398

399

400

401

402

403

404

405

406

407

408

409

410

411

412

413

414

415

all the colonies presenting a unique MLG. Mean genotypic diversity $\left(G_{O} / G_{E}\right)$ per island ranged from 0.34 for Saint Lucia (0.34 $\pm 0.25 ; n=2)$ and Saint Vincent $(0.34 \pm 0.25 ; n=3)$ to 1 for Saba. Mean genotypic evenness $\left(G_{O} / N_{g}\right)$ per island ranged from $0.52 \pm 0.31(\mathrm{n}=2$, Saint Lucia) to $0.96 \pm 0.03\left(\mathrm{n}=3\right.$, Saint-Martin). Genotypic evenness for Saba was maximal $\left(G_{O} / N_{g}=1\right)$ because all the colonies of the single sampling site of the island presented unique MLGs. High observed standard errors illustrate the unevenness of genotypic indices estimated among sites of a same island (Table 1).

\section{Genetic diversity}

Keeping only one representative per MLG $\left(N_{g}=718\right)$, observed heterozygosity $\left(H_{O}\right)$ across loci ranged between 0.493 for PAC10 in Saint Vincent and 0.714 for PAC11 in Bequia (mean \pm s.e. $=$ $0.624 \pm 0.008$; Table 1). Across all loci, expected heterozygosity $\left(H_{E}\right)$ per site ranged between 0.571 for PAC09 in Saint Vincent and 0.742 for IP in Guadeloupe (mean $=0.684 \pm 0.006$; Table 1). Estimated $F_{\text {IS }}$ per site across all loci ranged between -0.001 and 0.215 , respectively for LM in Guadeloupe and for PAC10 in Saint Vincent and significant departures from Hardy-Weinberg equilibrium were found in 17 out of 36 sampling sites, and 12 remained significant after Bonferroni correction (all heterozygote deficits, Table 1). Among the 3,278 pairwise tests of linkage disequilibrium comparing all loci at each of the 36 sampling sites, only 5 were significant after Bonferroni correction $(0.15 \%, P<0.05)$. Overall loci, estimated allelic richness $(A R)$ per site ranged from 87.5 for PAC20 in Antigua to 191.6 for PT in Guadeloupe (Table 1). Observed and expected heterozygosity estimates per locus within study sites, as well as per locus $F_{\text {IS }}$ are provided in Online Resource 2.

When grouping sites per island (i.e. considering that each island represents a population), mean observed heterozygosity across all loci ranged between $0.553 \pm 0.031$ for Saint Vincent and $0.663 \pm 0.051$ for Bequia (Table 1), mean expected heterozygosity ranged between $0.618 \pm 0.027$ for Saint Vincent and $0.704 \pm 0.023$ for Bequia, and mean allelic richness ranged from $102.1 \pm 8.6$ for Antigua to $137.0 \pm 7.4$ for Guadeloupe (mean overall islands $=125.6 \pm 4.1$ ), where a higher number of diverse sites were sampled. The smallest allelic richness estimates were 
421

422

423

424

425

426

427

428

429

430

431

432

433

434

435

436

437

found in Antigua, St Vincent (mean over 3 sites: $106.9 \pm 5.7$ ), Bequia (105.2 in one site, the other one being composed of clones) and Union (106.1 in one site).

Because the proportion of null alleles for marker \#1490 exceeded 20\% in most of the populations of the sampling sites (Online Resource 2; $n=25 / 36$ ), this marker, initially kept for MLG identification, was further excluded for the following genetic connectivity analyses (Chapuis and Estoup 2007).

\section{Population structure}

As a single MLG was found for FjL in Guadeloupe and for PAC09 in Saint Vincent, each MLG from these monoclonal sites was pooled with the genotypes of the closest site, respectively FjPE (2.1 km of distance) and PAC10 (1 km of distance), in order to keep the maximum of genetic information for further analyses.

Matrices of pairwise- $F_{\mathrm{ST}}$ estimated using GENEPOP and FREENA were highly related $\left(\mathrm{R}^{2}=0.94\right.$, $\mathrm{P}<0.0001)$. Because of the presence of null alleles in nearly all loci (Online Resource 2), we decided to present only the estimates from FREENA, which were estimated taking into account the occurrence of null alleles (though estimated based on HW equilibrium, an assumption unlikely met).

Within Guadeloupe, a weak genetic structure was observed among the 13 sampled sites, with only two pairs of sites significantly differentiated from each other: Anse Laborde (AL) and Tête à l'Anglais $(\mathrm{TA})\left(F_{\mathrm{ST}}=0.020^{*}\right)$, which are located on distinct geographic part of Guadeloupe (Grande Terre and Basse Terre, respectively), and Caye à Dupont (CD) and Anse à la Barque (PAC28) $\left(F_{\mathrm{ST}}=0.011^{*}\right.$, Online Resource 3), located on the opposite sides of Basse Terre (Figure 1). Accordingly, no apparent clusters were identified by STRUCTURE among the sampling sites of Guadeloupe. Based on the PCoA results, this observed genetic structure was further not in agreement with the geographic distribution of the sampling sites of Guadeloupe (Online Resource 4).

This weak genetic differentiation observed among sites within a single island was confirmed in all other islands of the Lesser Antilles under study, showing in general low and non-significant 
pairwise $F_{\text {ST }}$ estimates within islands (Online Resource 3). Indeed, the variance attributed to the

450

451

452

453

454

455

456

457

458

459

460

461

462

463

464

465

466

467

468

469

470

471

472

473

474

475

476

genetic variation estimated among sites within islands was weak and not significant (AMOVA: vb

$=0.0129 ;$ percentage of variation $=0.29 \%, \mathrm{p}$-value $=0.175$ ). Also, there was globally no

significant differentiation observed among sites belonging to the closest islands: no significant differentiations were reported among sampling sites of the northern islands St. Martin, St.

Barthélemy, Saba and Antigua (with the exception of a single significant pairwise $F_{\mathrm{ST}}$ estimate between one site in Antigua (PAC20) and one site in St. Barthélemy (SB3), $F_{\mathrm{ST}}=0.019 *$, Online

Resource 3). Similarly, no significant genetic differentiations were reported among sites of St.

Lucia and St. Vincent, nor among sites of the southern islands of St. Vincent, Bequia and Union

(with the exception of a single weak but significant pairwise $F_{\mathrm{ST}}$ estimate between one site in

Bequia (PAC12) and the single site of Union (PAC13), $F_{\mathrm{ST}}=0.009 *$, Online Resource 3 ).

In general, at the Lesser Antilles scale, no apparent differentiated clusters were identified when performing Bayesian assignment tests (STRUCTURE; data not shown). However, a weak but significant variance was attributed to the genetic variation estimated among islands (va = 0.0685 ; percentage of variation $=1.52 \%$, $\mathrm{p}$-value $<0.0001$ ), and the genetic differentiation between islands was generally higher than within island (Online Resource 3). Accordingly, geographic distances among sites significantly explained 35\% of the genetic variation $\left(F_{\mathrm{ST}} /\left(1-F_{\mathrm{ST}}\right)\right)$ across all sampling sites $(\mathrm{P}<0.0001$, Figure $4 \mathrm{~A})$. Furthermore, when sampling sites with less than 10 distinct genotypes were removed, geographic distances explained $46 \%$ of the genetic variation $(\mathrm{P}<0.0001$, Figure 4B), and up to $78 \%$ when sites with less than 20 genotypes were removed $(\mathrm{P}<0.001$, Figure 4C). Therefore, because of a restricted number of genotypes at some sites together with the general weak and non-significant genetic differentiation observed among sites within the same islands, the sites of each single island were pooled to run subsequent data analyses, resulting in 11 populations of $A$. palmata, corresponding to the 11 islands sampled across the Lesser Antilles.

A principal coordinates analysis (PCoA) conducted on these 11 island populations revealed that principal components 1 and 2 represented $86.29 \%$ (cumulated inertia of both axes) of the genetic heterogeneity among populations of A. palmata (Figure 5). Most importantly, Axis 1 with 
$72.88 \%$ of inertia segregated the 11 populations along a north/south gradient (Figure 5). In addition, populations of closed islands were generally not significantly differentiated (Table 2). Accordingly, geographic distances among islands significantly explained $72 \%(\mathrm{P}<0.0001)$ of the genetic variation $\left(F_{\mathrm{ST}} /\left(1-F_{\mathrm{ST}}\right)\right)$ among islands (Figure $\left.4 \mathrm{D}\right)$, revealing a clear Isolation-byDistance (IBD) pattern among A. palmata populations in the Lesser Antilles. This IBD pattern was further evidenced at the reef scale. Indeed, colonies sampled within a single site (or reef) $(<10 \mathrm{~km})$ were significantly more genetically similar than colonies belonging to distinct sampling sites, with decreasing similarity among colonies as the geographic distance among sampling sites increased (though still significant within distances up to $192 \mathrm{~km}$, Figure 6). Based on Loiselle's kinship coefficient and its regression on the natural logarithm of geographic distance using the iterative procedure, we were able to estimate a neighborhood size of A. palmata in the Lesser Antilles ranging between 82 and 130 individuals (with a mean over iterations cycling of 106 individuals). Reported densities of $A$. palmata range from 1,000 to 27,000 genets $/ \mathrm{km}^{2}$ across various Caribbean reefs (Baums et al. 2006a), and 2,000 to 25,000 genets $/ \mathrm{km}^{2}$ across the Lesser Antilles (Japaud et al. 2015, and estimates from the present study). Giving these estimated bounds for $D$ and assuming $D e=2000$ as the upper limit and $D e=10$ genets $/ \mathrm{km} 2$ as the lower limit of estimates of effective population densities, we estimated a gene dispersal $\sigma$ to be between 0.072 and $1.037 \mathrm{~km}$, with a gene dispersal longer at lower densities. Lastly, while the genetic variation among $A$. palmata populations seemed organized along a north-south axis (see Figure 5), we did not evidence a significant directional gene flow among islands. Indeed, a single relative directional migration coefficient $\left(D_{M}\right)$ appeared significant, from Union northward to Guadeloupe ( $\alpha=0.05$; Table 3). Nevertheless, when subtracting $D_{M}$ coefficients of each island pair estimated from a southward direction to $D_{M}$ coefficients of the same pair, but estimated from the northward direction, positive values (obtained when $D_{M}$ coefficients estimated from a northward direction were higher than those estimated from the southward one), were obtained in 36 out of 55 pairwise comparisons (65\%), suggesting a general northward gene flow (though not significant), among A. palmata populations along the arc of the Lesser Antilles. 


\section{Discussion}

507

508

509

510

511

512

513

514

The molecular analysis of 1,042 A. palmata sampled colonies using a set of 14 microsatellite loci revealed that 8 individuals identified in the field as A. palmata on the basis of their morphological characteristics showed MLGs genetically close to A. prolifera MLGs. These samples were therefore removed from the A. palmata dataset. Using this same set of microsatellite loci, it was found that clonality proportion greatly varied among sampling sites. Hence, some A. palmata stands presented large patch of clones with a single MLG while others were only composed of colonies with distinct MLGs, even if the sampling sites were located on a same island (as in Guadeloupe for example). Nevertheless, mean genotypic index estimates across all sampling sites of the Lesser Antilles globally illustrated high genotypic richness and evenness $\left(\mathrm{Ng} / \mathrm{N}=0.75 \pm 0.04 ; \mathrm{Go}_{\mathrm{o}} / \mathrm{Ng}=0.79 \pm 0.04\right)$. Regarding the genetic structuring of A. palmata populations of the Lesser Antilles, no apparent distinct clusters were identified. Nevertheless, pairwise genetic distances were correlated to geographic distances among populations, revealing an isolation-by-distance pattern with a maximum estimated gene dispersal for A. palmata of one kilometer.

\section{Gene introgression from Acropora cervicornis to Acropora palmata}

Several colonies were genetically identified as A. prolifera hybrids after being morphologically identified as A. palmata (see for example Online Resource 5). The 'palmate-morph' defined by (Vollmer and Palumbi 2002) for some A. prolifera F1 hybrids is not sufficient to explain a complete confusion in colony morphological identification. Rare backcrossing of A. palmata with the first generation hybrid A. prolifera may induce later generation hybrids and a consequent introgression of A. cervicornis genes into A. palmata genome, which may explain that some colonies genetically identified as A. prolifera could present a confusing A. palmata morphology (Miller and van Oppen 2003; Fogarty 2012). This observation suggests that the hybridization complex of Caribbean Acropora species may be more complicated that a unidirectional introgression of genes flowing from A. palmata towards A. cervicornis as previously described 
533

534

535

536

537

538

539

540

541

542

543

544

545

546

547

548

549

550

551

552

553

554

555

556

557

558

559

(van Oppen et al. 2000; Vollmer and Palumbi 2002, 2007; Fogarty et al. 2012). Further investigations are needed 1) to evaluate how observed decreasing densities of both A. palmata and $A$. cervicornis may explain increasing observations of large thickets of this hybrid across the Caribbean (Japaud et al. 2014; Aguilar-Perera and Hernández-Landa 2017) and a decreased mortality of these hybrids in recent decades (Fogarty 2012), and 2) to evaluate how the increasing success of this hybrid may affect both $A$. palmata and A. cervicornis populations.

\section{Possible influence of site-specific environmental conditions on clonality}

In this study, estimates of genotypic indices varied considerably among sampling sites, even among closed sites or sites located within a same island. Mean genotypic richness per site was 0.75, smaller than estimates available for A. palmata western lineage and previously reported $(\mathrm{Ng} / \mathrm{N}=0.96$ in Guadeloupe, Mège et al. 2015); $\mathrm{Ng} / \mathrm{N}=0.86$ and 0.94 in Los Roques National Park, Venezuela, in Porto-Hannes et al. (2015). However, in these two cited studies, as well as in the present work, genotypic richness estimates varied greatly among sites (from 0.38 to 1.00 in Mège et al. (2015); from 0.65 to 0.98 in Porto-Hannes et al. (2015) and from 0.03 to 1.00 in here). Similarly to Mège et al. (2015) and Porto-Hannes et al. (2015), an opportunistic sampling strategy (i.e. sampling haphazardly) was adopted to assess genetic structure of the A. palmata populations of the Lesser Antilles (and to avoid an overrepresentation of clones) since specifically characterizing genotypic diversity and clonality of these populations was not our primary goal. For this reason, population dynamics implications based on the genotypic indices estimates should be interpreted carefully. Indeed, our estimates were higher than found in Baums et al. (2006a) who specifically investigated levels of clonality in this species using either a randomized sampling strategy (i.e. sampling colonies a priori selected following a procedure generating random coordinates, see Baums et al. 2005a) or an opportunistic sampling strategy (mean \pm SD $N_{g} / N$ per site $=0.52 \pm 0.26$ and $0.51 \pm 0.31$, respectively), even when compared to sampling sites from the western lineage only (mean \pm SD $N_{g} / N$ per site $=0.64 \pm 0.18$ and $0.71 \pm 0.01$, respectively). 
560

561

562

563

564

565

566

567

568

569

570

571

572

573

574

575

576

577

578

579

580

581

582

583

Nevertheless, the difference in estimates of genotypic richness may result from differences in site-specific environmental conditions rather than other factors like a difference in sampling strategy (Mège et al. 2015). For example, in our study, estimates of genotypic indices were low and consistent across sampling sites presenting somehow similar environmental characteristics than of Caye à Dupont. a site where A. palmata clonality was specifically investigated using an exhaustive sampling within a 30 m radius circle (Japaud et al. 2015) and for which it was found a $N_{g} / N=0.125$. This reef, as well as Duvernette Island reef $\left(N_{g} / N=0.14\right)$, Blue Lagoon reef $\left(N_{g} / N\right.$ $=0.17)$ in St Vincent, and Ilet Fajou reef in Guadeloupe $\left(N_{g} / N=0.03\right)$ were all characterized by high hydrodynamism, a shallow flat bottom and a high coral colony density, constituting a set of general characteristics that seems to advantage the asexual expansion of the branching Acropora corals (Japaud et al. 2015). Indeed, the proportion of asexual reproduction by fragmentation in a population is known to be related to site-specific geoclimatic conditions such as intensity and frequency of swell, waves, hurricanes and topography (Coffroth and Lasker 1998; Baums et al. 2006b). In contrast, reefs where A. palmata stands presented few or no clones could be related to areas with less suitable habitat and low population densities (Mège et al. 2015). Alternatively, A. palmata populations presenting scarce colonies with few or no clones could be relicts of old and dense populations which faced past important stressor events (such as "white band" disease, coral bleaching, hurricanes, algal over-growth or predation...), resulting in losses of colonies without any subsequent efficient recovery (Bruckner 2002; Acropora Biological Review Team 2005). Future studies investigating the recent demographic history of these populations sequencing large fractions of genomes analysed with Approximate Bayesian Computation

(Beaumont et al. 2002) may specifically allow to test for this hypothesis (Hoffman et al. 2011).

\section{Low genetic diversity estimates for Acropora palmata in the Lesser Antilles}

Resilience of populations depends on genetic diversity that is necessary to the species adaptation success facing changes in environmental conditions (Miller and Ayre 2004; Yeoh and Dai 2009). In A. palmata, the genetic diversity estimated in the present study was globally lower (mean $H_{E}$ per site $=0.684 \pm 0.038$ ) than any estimates of genetic diversity found in similar 
588

589

590

591

592

593

594

595

596

597

598

599

600

601

602

603

604

605

606

607

608

609

610

611

612

613

614

615

studies conducted by Baums et al. (2005b), Mège et al. (2015) and Porto-Hannes et al. (2015) with $H_{E}$ per site $=0.75,0.761$ and 0.869 , respectively. These differences in genetic diversity can partly be explained by the fact that different microsatellite loci were used in the present study: 14 loci were used here, including the five loci exclusively used in the previous studies of Baums et al. (2005b) and Mège et al. (2015) and the four loci exclusively used in Porto-Hannes et al. (2015). Therefore, to compare our estimates of genetic diversity to those found in the previous published studies, the five common loci were kept to re-estimate previous indices (Online Resource 6). This new computation indeed increased the estimated genetic diversity per site of the present study (mean $H_{E}=0.71$ ), though it remained globally lower than those published in similar A. palmata studies. When comparing our genetic diversity estimates with those available for the western lineage only, we found that estimates in Guadeloupe (mean $H_{E}=0.73$ overall sites) were similar to those previously reported for this same island $\left[H_{E}=0.74\right.$ in Mège et al. (2015)], but for St. Vincent and the Grenadines (SVG), the genetic diversity $\left(H_{E}=0.65\right)$ was slightly lower than those reported by Baums et al. (2005b) $\left(H_{E}=0.69\right)$. This difference may partially be explained by the monoclonal site PAC09 on Duvernette Island, south St. Vincent $\left(H_{E}=0.40\right.$ for PAC09 with the five common loci). Lower levels observed in the Lesser Antilles when compared to other Caribbean reefs, and even reefs off the Venezuelan coast (Baums et al. 2005b; Mège et al. 2015, Porto-Hannes et al. 2015) may be of particular concern for the resilience capacity of particular $A$. palmata populations in case of eventual disturbances, given their location at the eastern boundary of the Caribbean Sea and their genetic isolation from the west lineage. Nevertheless, the genetic diversity is not the only factor to take into account to predict population resilience ability. Indeed, reproduction modes and recruitment are also critical (Ayre and Hughes 2000; Knowlton 2001).

Acropora palmata is a broadcast-spawning coral species. During massive reproductive events, the probability of gametes meeting in open-ocean is enhanced by high densities of gametes synchronically released by a high number of colonies. Since A. palmata is an obligate outcrosser, the production of larvae issued from sexual reproduction is only possible after fertilization between gametes produced by genetically distinct colonies (Fukami et al. 2003; Baums et al. 
2005a). Therefore, since efficient recruitment of larvae issued from sexual reproduction enhances population genetic diversity, lower diversity levels may be related to a deficit in sexually produced recruits linked with unfavourable conditions. Indeed, it has been shown that recovery of A. palmata populations from larval recruitment issued from sexual reproduction may be limited following environmental perturbations (Quinn and Kojis 2005; Bouchon et al. 2008; Williams et al. 2008).

In a recent study, Miller et al. (2016) reported that different genotypes of a single A. palmata population did not participate synchronically to the reproduction event, or even systematically every year. Therefore, because small colonies were not targeted during our sampling in order to avoid oversampling clones, low levels of genetic diversity may result from a bias linked to our sampling strategy. Indeed, the genetic diversity estimates from our sampled coral colonies may rather reflect genetic diversity levels from past recruitment events, e.g. the last years or decades, than current levels from integrated generations. Without stress events, a coral colony may live for decades or centuries, but because of branch breakage and regrowth, estimating the age of a coral colony (i.e. physical individual) from its size remains hazardous. Therefore, it is difficult to evaluate at which point the observed results obtained from potential relict colonies truly reflect the current situation. In conclusion, estimating genetic diversity could not be sufficient to predict resilience of A. palmata populations of the Lesser Antilles without taking into account sexual reproduction and larval recruitment. An examination of the genetic diversity within recruits is therefore warranted.

\section{Isolation-by-distance and limited larval dispersal}

Previous studies using five microsatellite loci showed that the Caribbean A. palmata population was genetically divided into two distinct lineages, with the northern break found around the Puerto Rican region (Baums et al. 2005b, 2006b, a; Mège et al. 2015). Therefore, considering the location of the Lesser Antilles, we hypothesized that the populations of the 11 sampled islands in the present study belong to the eastern phylogeographic lineage. This was confirmed here since we did not identify distinct genetic clusters among the A. palmata populations analysed. 
644

645

646

647

648

649

650

651

652

653

654

655

656

657

658

659

660

661

662

663

664

665

666

667

668

669

670

671

Nevertheless, a significant genetic structure was found among A. palmata sampled populations, revealing, for the first time, a pattern in agreement with the geographical seascape. Indeed, it was found that A. palmata gene flow in the Lesser Antilles was oriented along a north-south axis, with increasing genetic divergence related to increasing geographic distance among islands. This IBD pattern was identified both at the reef scale (since individuals within short distance classes up to $192 \mathrm{~km}$ were significantly more related than between distance classes), and at the Antilles Arc scale, among geographically isolated populations. Though such IBD has already been found in A. palmata, it was restricted to the Puerto Rican sea shore and attributed to a genetic admixture zone between western and eastern lineages (Mège et al. 2014). Within each lineage, no IBD pattern were reported among $A$. palmata populations in previous studies for which the sampling scheme allowed to test for an IBD at a local scale. Indeed, within the western lineage, the weak genetic differentiation observed along the Mesoamerican Barrier Reef System was not related to geographic distances among sampling sites (Porto-Hannes et al. 2015), and within the eastern lineage, the three sampled populations of Culebra (north Puerto Rico), Guadeloupe and Curaçao were not found to be significantly differentiated (Mège et al. 2014).

The specific geographic context of the Lesser Antilles archipelago, with small islands more or less regularly spaced from each other by few kilometers and further aligned along a north-south axis likely explains the observed IBD among $A$. palmata populations. An IBD pattern usually characterizes populations with limited connectivity across different suitable habitat patches, reflecting gene flow occurring in a stepping-stone model. That is already known in several corals and other marine species, with limited larvae dispersal, studied among fragmented habitat patches (Palumbi 2003; Cowen et al. 2006; Galindo et al. 2006; Hellberg 2007; Andras et al. 2013; Postaire et al. 2017). Indeed, for marine sessile species like corals, gene flow among populations depends on the first living stages of these organisms, mostly insured by reproductive outputs (gametes), fertilized eggs and pelagic larvae. In $A$. palmata, the larval pelagic phase is recognized as relatively short since Acropora larvae are competent to settle 3 to 5 days after fertilization (Fogarty 2010, 2012). With a larval phase of 4-5 days, the potential of dispersal for Caribbean Acropora pelagic larvae has been estimated to several tens of kilometres 
672

673

674

675

676

677

678

679

680

681

682

683

684

685

686

687

688

689

690

691

692

693

694

695

696

697

698

699

(Baums et al. 2005; Hemond and Vollmer 2010; Drury et al. 2018), with possible local retention up to $47.5 \%$ on specific reefs (Drury et al. 2018). Nevertheless, it has been shown that, depending on the environmental constraining conditions, the pelagic phase for A. palmata larvae may last up to 20 days (Harrison and Wallace 1990; Hayashibara et al. 1993; Baums et al. 2005b; Hemond and Vollmer 2010; Ritson-Williams et al. 2010), suggesting a higher dispersal potential. Although our estimates of $\sigma$, half the mean square parent-offspring distance, vary giving the value of the effective population density $(D e)$ used for the computations (between $70 \mathrm{~m}$ to $\mathrm{ca} .1$ $\mathrm{km}$ ), our results suggest that gene dispersal is highly restricted by geographic distances, which confirm that the capacity of dispersal among A. palmata populations of the Lesser Antilles islands is likely very limited. Yet, this dispersal kernel is likely facilitated by oceanic sea surface currents (Heck and McCoy 1978; Veron 1995), which show a dominant north-west direction during A. palmata spawning period (Online Resource 7). Indeed, even if a significant northward gene flow along the Lesser Antilles could not be significantly demonstrated over the Lesser Antilles, $65 \%$ of the observed $D_{M}$ estimates suggest a same direction for $A$. palmata gene flow and main oceanic sea surface currents. This finding still need further investigations, with additional samples originating from the southern Caribbean reefs. If confirmed, it would imply that southern reefs act as source of gametes and larvae to the Lesser Antilles, an hypothesis also suggested by (Baums et al. 2005b).

\section{Consequences for resilience and conservation of endangered Acropora palmata}

\section{populations in the Lesser Antilles}

Globally, the present results reveal that the genetic diversity of $A$. palmata populations of the Lesser Antilles is lower than previously estimated for A. palmata populations of the Caribbean region. This is of great concern since lower genetic diversity may reduce the resilience ability against environmental perturbations (Reush et al. 2005). Additionally, observed northward gene flow through the Lesser Antilles archipelago, together with the southern known boundary of the eastern A. palmata lineage (Baums et al. 2005b; Mège et al. 2014) suggest that populations from the southernmost islands of the Lesser Antilles (likely including Grenada, Trinidad and Tobago 
and the Leeward Antilles), and those of the north coast of South America (at least Venezuela), have a potential key role in broadcasting larvae to the more northern islands of the Lesser Antilles. If confirmed, preserving these southernmost $A$. palmata populations should be a priority, especially since the southern populations analyzed in our study (St Vincent, Union and Bequia) showed the smallest allelic richness estimates, together with Antigua. Yet, because of the heterogeneous societal and institutional situation of the Lesser Antilles, conservation aspects to protect $A$. palmata at a regional scale may be difficult to implement.

Promoting genetic diversity through a high genotypic diversity seems to be the basis for viable and sustainable restoration projects of coral populations. In the Lesser Antilles, as well as in other parts of the Caribbean Sea, a great number of restoration projects for A. palmata populations have been undertaken in the last decades, mainly through the transplantation of colonies issued from fragments (Young et al. 2012; Lirman et al. 2014). As discussed above, it is crucial to insure genotypic diversity within these restored fragments. In this context, other restoration projects were carried out by transplanting colonies issued from sexual reproduction after gametes collection in natural populations (Chamberland et al. 2015). Nevertheless, this strategy requires a preliminary evaluation of potential source populations of gametes. As genotypic richness is negatively correlated with colony density (Baums et al. 2006a), denser A. palmata populations, likely composed of numerous clones, may not represent the best sources of gametes. On the opposite, scattered populations may exhibit higher genotypic richness, although producing less gametes. Knowing this trade-off, a high density of colonies in a population may not therefore be a sufficient criterion to select source populations of A. palmata gametes and fragments for transplantation.

Additionally, we showed that the genetic structure of $A$. palmata populations of the Lesser Antilles exhibit an isolation-by-distance pattern, both at the reef scale among individuals and at the Antilles Arc scale (sampling extending over c.a. 1,000 km) among geographically isolated populations. Thus, the hypothesis of genetic adaptation of A. palmata colonies to local and specific environmental conditions, even at limited spatial scale, may not be ruled out (DevlinDurante and Baums 2017). In this context, enhancing genetic diversity of reefs through the 
729 be suitable if source populations are not fully adapted to the local environmental conditions of

730 the transplantation sites (Baums 2008; Devlin-Durante and Baums 2017). Therefore, special

731 attention must be paid to the selection of the source populations for collecting fragments or

73 gametes for coral reef restoration projects, not only regarding the density of coral colonies and their genotypic richness but also regarding the genetic divergence between the source population and that of the transplantation site. 


\section{References}

Acropora Biological Review Team (2005) Atlantic Acropora Status Review

Aguilar-Perera A, Hernández-Landa RC (2017) Occurrence of large thickets of Acropora prolifera (Scleractinia: Acroporidae) in the southern Gulf of Mexico. Mar Biodivers 1-3. doi: 10.1007/s12526-017-0685-4

Andras JP, Rypien KL, Harvell CD (2013) Range-wide population genetic structure of the Caribbean sea fan coral, Gorgonia ventalina. Mol Ecol 22:56-73. doi: 10.1111/mec.12104

Aronson RB, Bruckner AW, Moore JA, et al (2008) Acropora cervicornis. IUCN Red List Threat Species e.T133381A3716457

Ayre DJ, Hughes TP (2000) Genotypic diversity and gene flow in brooding and spawning corals along the Great Barrier Reef, Australia. Evolution 54:1590-1605. doi: 10.1111/j.00143820.2000.tb00704.x

Bak RPM (1975) Ecological aspects of the distribution of reef corals in the Netherlands Antilles. Bijdr Tot Dierkd 45:181-190

Baums IB (2008) A restoration genetics guide for coral reef conservation. Mol Ecol 17:2796-2811. doi: 10.1111/j.1365-294X.2008.03787.x

Baums IB, Devlin-Durante MK, Brown L, Pinzón JH (2009) Nine novel, polymorphic microsatellite markers for the study of threatened Caribbean acroporid corals. Mol Ecol Resour 9:11521158. doi: 10.1111/j.1755-0998.2009.02588.x

Baums IB, Hughes CR, Hellberg ME (2005a) Mendelian microsatellite loci for the Caribbean coral Acropora palmata. Mar Ecol Prog Ser 288:115-127. doi: 10.3354/meps288115

Baums IB, Miller MW, Hellberg ME (2005b) Regionally isolated populations of an imperiled Caribbean coral, Acropora palmata. Mol Ecol 14:1377-1390. doi: 10.1111/j.1365-294X.2005.02489.x

Baums IB, Miller MW, Hellberg ME (2006a) Geographic variation in clonal structure in a reef-building Caribbean coral, Acropora palmata. Ecol Monogr 76:503-519

Baums IB, Paris CB, Chérubin LM (2006b) A bio-oceanographic filter to larval dispersal in a reefbuilding coral. Limnol Oceanogr 51:1969-1981

Beaumont MA, Zhang W, Balding DJ (2002) Approximate Bayesian computation in population genetics. Genetics 162:2025-2035

Belkhir K, Borsa P, Chikhi L, et al (2004) GENETIX 4.05, logiciel sous Windows TM pour la génétique des populations. Lab Génome Popul Interact CNRS UMR 5000 Univ Montp II Montp Fr

Bouchon C, Portillo P, Bouchon-Navaro Y, et al (2008) Status of Coral Reefs of the Lesser Antilles : The French West Indies, The Netherlands Antilles, Anguilla, Antigua, Grenada, Trinidad and Tobago. In: Status of Coral Reefs of the World: 2008. pp 265-280

Bruckner AW (2002) Proceedings of the Caribbean Acropora Workshop: Potential Application of the U.S. Endangered Species Act as a Conservation Strategy. In: Proceedings of the Caribbean Acropora Workshop. p 199 
Carpenter KE, Abrar M, Aeby GS, et al (2008) One-third of reef-building corals face elevated extinction risk from climate change and local impacts. Science Supplementary Material

Chamberland VF, Vermeij MJA, Brittsan M, et al (2015) Restoration of critically endangered elkhorn coral (Acropora palmata) populations using larvae reared from wild-caught gametes. Glob Ecol Conserv 4:526-537. doi: 10.1016/j.gecco.2015.10.005

Chapuis M-P, Estoup A (2007) Microsatellite null alleles and estimation of population differentiation. Mol Biol Evol 24:621-631. doi: 10.1093/molbev/msl191

Coffroth MA, Lasker HR (1998) Population structure of a clonal gorgonian coral: the interplay between clonal reproduction and disturbance. Evolution 52:379-393

Cowen RK, Paris CB, Srinivasan A (2006) Scaling of connectivity in marine populations. Science 311:522-527. doi: 10.1126/science.1122039

Dempster AP, Laird NM, Rubin DB (1977) Maximum likelihood from incomplete data via the EM algorithm. J R Stat Soc Ser B Methodol 39:1-38

Devlin-Durante MK, Baums IB (2017) Genome-wide survey of single-nucleotide polymorphisms reveals fine-scale population structure and signs of selection in the threatened Caribbean elkhorn coral, Acropora palmata. PeerJ 5:e4077. doi: 10.7717/peerj.4077

Earl DA, VonHoldt BM (2012) STRUCTURE HARVESTER: A website and program for visualizing STRUCTURE output and implementing the Evanno method. Conserv Genet Resour 4:359361. doi: 10.1007/s12686-011-9548-7

Evanno G, Regnaut S, Goudet J (2005) Detecting the number of clusters of individuals using the software STRUCTURE: A simulation study. Mol Ecol 14:2611-2620. doi: 10.1111/j.1365294X.2005.02553.x

Excoffier L, Lischer HEL (2010) Arlequin suite ver 3.5: a new series of programs to perform population genetics analyses under Linux and Windows. Mol Ecol Resour 10:564-567. doi: 10.1111/j.1755-0998.2010.02847.x

Excoffier L, Smouse PE, Quattro JM (1992) Analysis of molecular variance inferred from metric distances among DNA haplotypes: application to human mitochondrial DNA restriction data. Genetics 131:479-491

Faircloth BC (2006) GMCONVERT : file conversion for GENEMAPPER output files. Mol Ecol Notes 6:968-970. doi: 10.1111/j.1471-8286.2006.01419.x

Fogarty ND (2012) Caribbean acroporid coral hybrids are viable across life history stages. Mar Ecol Prog Ser 446:145-159. doi: 10.3354/meps09469

Fogarty ND (2010) Reproductive isolation and hybridization dynamics in threatened Caribbean Acroporid corals. Nova Southeastern University

Fogarty ND, Vollmer S V., Levitan DR (2012) Weak prezygotic isolating mechanisms in threatened Caribbean Acropora corals. PLoS ONE 7:e30486. doi: 10.1371/journal.pone.0030486

Francisco-Ortega J, Santiago-Valentín E, Acevedo-Rodríguez P, et al (2007) Seed plant genera endemic to the Caribbean Island biodiversity hotspot: A review and a molecular phylogenetic perspective. Bot Rev 73:183-234. doi: 10.1663/0006-8101(2007)73[183:SPGETT]2.0.CO;2 
Fukami H, Omori M, Shimoike K, et al (2003) Ecological and genetic aspects of reproductive isolation by different spawning times in Acropora corals. Mar Biol 142:679-684. doi: 10.1007/s00227002-1001-8

Galindo HM, Olson DB, Palumbi SR (2006) Seascape genetics: a coupled oceanographic-genetic model predicts population structure of Caribbean corals. Curr Biol 16:1622-1626. doi: 10.1016/j.cub.2006.06.052

Garcia Reyes J, Schizas N (2010) No two reefs are created equal: fine-scale population structure in the threatened coral species Acropora palmata and A. cervicornis. Aquat Biol 10:69-83. doi: $10.3354 / \mathrm{ab00254}$

Goreau TF (1959) The ecology of Jamaican coral reefs I. Species composition and zonation. Ecology 40:67-90. doi: 10.2307/1929924

Hardy OJ, Vekemans X (2002) SPAGEDI: a versatile computer program to analyse spatial genetic structure at the individual or population levels. Mol Ecol Notes 2:618-620. doi: 10.1046/j.1471-8278

Hardy OJ, Vekemans X (1999) Isolation by distance in a continuous population: reconciliation between spatial autocorrelation analysis and population genetics models. Heredity 83:145154

Harrison PL, Wallace CC (1990) Reproduction, dispersal and recruitment of scleractinian corals. In: Dubinsky Z (ed) Ecosystems of the world - Coral reefs. Elsevier, Amsterdam, pp 133-207

Hayashibara T, Shimoike K, Kimura T, et al (1993) Patterns of coral spawning at Akajima Island, Japan. Mar Ecol Prog Ser 101:253-262

Heck KL, McCoy ED (1978) Long-distance dispersal and the reef-building corals of the Eastern Pacific. Mar Biol 48:349-356

Hedges SB, Díaz LM (2011) The Conservation Status Of Amphibians In The West Indies. In: Wilson BS, Hailey A, Horrocks JA (eds) Conservation of Caribbean Island Herpetofaunas Volume 1: Conservation Biology and the Wider Caribbean. Brill, pp 31-48

Hellberg ME (2007) Footprints on water: The genetic wake of dispersal among reefs. Coral Reefs 26:463-473. doi: 10.1007/s00338-007-0205-2

Hemond EM, Vollmer S V. (2010) Genetic diversity and connectivity in the threatened staghorn coral (Acropora cervicornis) in Florida. PLoS ONE 5:e8652. doi: 10.1371/journal.pone.0008652

Highsmith RC (1982) Reproduction by fragmentation in corals. Mar Ecol Prog Ser 7:207-226. doi: 10.3354/meps007207

Hoffman JI, Grant SM, Forcada J, Phillips CD (2011) Bayesian inference of a historical bottleneck in a heavily exploited marine mammal. Mol Ecol 20:3989-4008. doi: 10.1111/j.1365294X.2011.05248.x

Hughes AR, Inouye BD, Johnson MTJ, et al (2008) Ecological consequences of genetic diversity. Ecol Lett 11:609-623. doi: 10.1111/j.1461-0248.2008.01179.x

Jakobsson M, Rosenberg NA (2007) CLUMPP: A cluster matching and permutation program for dealing with label switching and multimodality in analysis of population structure. Bioinformatics 23:1801-1806. doi: 10.1093/bioinformatics/btm233 
Japaud A, Bouchon C, Manceau JL, Fauvelot C (2015) High clonality in Acropora palmata and Acropora cervicornis populations of Guadeloupe, French Lesser Antilles. Mar Freshw Res 66:847. doi: $10.1071 / \mathrm{mf14181}$

Japaud A, Fauvelot C, Bouchon C (2014) Unexpected high densities of the hybrid coral Acropora prolifera (Lamarck 1816) in Guadeloupe Island, Lesser Antilles. Coral Reefs 33:593-593. doi: 10.1007/s00338-014-1169-7

Jost L (2008) GST and its relatives do not measure differentiation. Mol Ecol 17:4015-4026. doi: 10.1111/j.1365-294X.2008.03887.x

Knowlton N (2001) The future of coral reefs. Proc Natl Acad Sci U A 98:5419-25. doi: 10.1073/pnas.091092998

Latta SC (2012) Avian research in the Caribbean: past contributions and current priorities. J Field Ornithol 83:107-121. doi: 10.1111/j.1557-9263.2012.00361.x

Lirman D (2000) Fragmentation in the branching coral Acropora palmata (Lamarck): growth, survivorship, and reproduction of colonies and fragments. J Exp Mar Biol Ecol 251:41-57

Lirman D, Schopmeyer S, Galvan V, et al (2014) Growth Dynamics of the Threatened Caribbean Staghorn Coral Acropora cervicornis: Influence of Host Genotype, Symbiont Identity, Colony Size, and Environmental Setting. PLOS ONE 9:e107253. doi: 10.1371/journal.pone.0107253

Loiselle BA, Sork VL, Nason J, Graham C (1995) Spatial genetic structure of a tropical understory shrub, PSYCHOTRIA OFFICINALIS (RuBIACEAE). Am J Bot 82:1420-1425. doi: 10.1002/j.15372197.1995.tb12679.x

Mantel N (1967) The detection of disease clustering and a generalized regression approach. Cancer Res 27:209-220

Mayr E (1963) Animal Species and Evolution. Cambridge: Harvard University Press. 797 pp.

Mège P, Schizas NV, Garcia Reyes J, Hrbek T (2015) Genetic seascape of the threatened Caribbean elkhorn coral, Acropora palmata, on the Puerto Rico Shelf. Mar Ecol 36:195-209. doi: 10.1111/maec.12135

Miller DJ, van Oppen MJH (2003) A "fair go" for coral hybridization. Mol Ecol 12:805-807

Miller KJ, Ayre DJ (2004) The role of sexual and asexual reproduction in structuring high latitude populations of the reef coral Pocillopora damicornis. Heredity 92:557-568. doi: 10.1038/sj.hdy.6800459

Miller MW, Williams DE, Fisch J (2016) Genet-specific spawning patterns in Acropora palmata. Coral Reefs. doi: 10.1007/s00338-016-1472-6

Miller WJ, Muller EM, Rogers CS, et al (2009) Coral disease following massive bleaching in 2005 causes 60\% decline in coral cover on reefs in the US Virgin Islands. Coral Reefs 28:925-937. doi: 10.1007/s00338-009-0531-7

Palumbi SR (2003) Population genetics, demographic connectivity, and the design of marine reserves. Ecol Appl 13:146-158. doi: 10.1890/1051-0761(2003)013[0146:PGDCAT]2.0.CO;2

Peakall R, Smouse PE (2006) GENALEX 6: Genetic analysis in Excel. Population genetic software for teaching and research. Mol Ecol Notes 6:288-295. doi: 10.1111/j.1471-8286.2005.01155.x 
Peakall R, Smouse PE (2012) GenALEx 6.5: Genetic analysis in Excel. Population genetic software for teaching and research-an update. Bioinformatics 28:2537-2539. doi: 10.1093/bioinformatics/bts460

Porto-Hannes I, Zubillaga AL, Shearer TL, et al (2015) Population structure of the corals Orbicella faveolata and Acropora palmata in the Mesoamerican Barrier Reef System with comparisons over Caribbean basin-wide spatial scale. Mar Biol 162:81-98. doi: 10.1007/s00227-014-25601

Postaire B, Gélin P, Bruggemann JH, Magalon H (2017) One species for one island? Unexpected diversity and weak connectivity in a widely distributed tropical hydrozoan. Heredity 1-10. doi: $10.1038 /$ hdy.2016.126

Precht WF, Bruckner AW, Aronson RB, Bruckner RJ (2002) Endangered acroporid corals of the Caribbean. Coral Reefs 21:41-42

Pritchard JK, Stephens M, Donnelly P (2000) Inference of population structure using multilocus genotype data. Genetics 155:945-959

Quinn NJ, Kojis BL (2005) Patterns of sexual recruitment of acroporid coral populations on the West Fore Reef at Discovery Bay, Jamaica. Rev Biol Trop 53:83-90

R Core Team (2016) R: A language and environment for statistical computing. R Found Stat Comput Vienna Austria ISBN 3-900051-07-0 URL HttpwwwR-Proj

Raymond M, Rousset F (1995) GENEPOP (Version 1.2): Population genetics software for exact tests and ecumenicism. J Hered 86:248-249

Reusch TBH, Ehlers A, Hämmerli A, Worm B (2005) Ecosystem recovery after climatic extremes enhanced by genotypic diversity. Proc Natl Acad Sci U S A 102:2826-2831. doi: 10.1073/pnas.0500008102

Ritson-Williams R, Paul VJ, Arnold SN, Steneck RS (2010) Larval settlement preferences and postsettlement survival of the threatened Caribbean corals Acropora palmata and A. cervicornis. Coral Reefs 29:71-81. doi: 10.1007/s00338-009-0555-z

Rossetto M, Gross CL, Jones R, Hunter J (2004) The impact of clonality on an endangered tree (Elaeocarpus williamsianus) in a fragmented rainforest. Biol Conserv 117:33-39. doi: 10.1016/S0006-3207(03)00260-X

Rousset (2000) Genetic differentiation between individuals. J Evol Biol 13:58-62. doi: 10.1046/j.14209101.2000.00137.x

Szmant AM (1986) Reproductive ecology of Caribbean reef corals. Coral Reefs 5:43-53. doi: 10.1007/BF00302170

Spalding MD, Fox HE, Allen GR, et al (2007) Marine Ecoregions of the World: A Bioregionalization of Coastal and Shelf Areas. BioScience 57:573-583

Stoddart JA, Taylor JF (1988) Genotypic diversity: Estimation and prediction in samples. Genetics 118:705-711

Sundqvist L, Keenan K, Zackrisson M, et al (2016) Directional genetic differentiation and relative migration. Ecol Evol 6:3461-3475. doi: 10.1002/ece3.2096 
Vallejo-Marín M, Dorken ME, Barrett SCH (2010) The Ecological and Evolutionary Consequences of Clonality for Plant Mating. Annu Rev Ecol Evol Syst 41:193-213. doi: 10.1146/annurev.ecolsys.110308.120258

van Etten J (2015) Package ' gdistance .' 1-30

van Loon EE, Cleary DFR, Fauvelot C (2007) ARES: Software to compare allelic richness between uneven samples. Mol Ecol Notes 7:579-582. doi: 10.1111/j.1471-8286.2007.01705.x

van Oosterhout C, Hutchinson WF, Wills DPM, Shipley P (2004) MICRO-CHECKER: Software for identifying and correcting genotyping errors in microsatellite data. Mol Ecol Notes 4:535538. doi: 10.1111/j.1471-8286.2004.00684.x

van Oppen MJH, Willis BL, van Vugt HWJA, Miller DJ (2000) Examination of species boundaries in the Acropora cervicornis group (Scleractinia, Cnidaria) using nuclear DNA sequence analyses. Mol Ecol 9:1363-1373

Vekemans X, Hardy OJ (2004) New insights from fine-scale spatial genetic structure analyses in plant populations. Mol Ecol 13:921-935. doi: 10.1046/j.1365-294X.2004.02076.x

Veron JEN (2000) Corals of the World: Volume 1. Townsville

Veron JEN (1995) Corals in space and time. The biogeography and evolution of the Scleractinia, Cornell Un. London

Vollmer S V., Palumbi SR (2002) Hybridization and the evolution of reef coral diversity. Science 296:2023-2025. doi: 10.1126/science.1069524

Vollmer S V., Palumbi SR (2007) Restricted gene flow in the Caribbean staghorn coral Acropora cervicornis: Implications for the recovery of endangered reefs. J Hered 98:40-50. doi: 10.1093/jhered/es1057

von der Heyden S, Beger M, Toonen RJ, et al (2014) The application of genetics to marine management and conservation: examples from the Indo-Pacific. Bull Mar Sci 90:123-158. doi: $10.5343 /$ bms.2012.1079

Wallace CC (1999) Staghorn Corals of the World: A Revision of the Coral Genus Acropora (Scleractinia; Astrocoeniina; Acroporidae) worldwide, with emphasis on morphology, phylogeny and biogeography

Weir BS, Cockerham CC (1984) Estimating F-statistics for the analysis of population structure. Evolution 38:1358-1370

Williams DE, Miller MW (2005) Coral disease outbreak: pattern, prevalence and transmission in Acropora cervicornis. Mar Ecol Prog Ser 301:119-128

Williams DE, Miller MW, Kramer KL (2008) Recruitment failure in Florida Keys Acropora palmata, a threatened Caribbean coral. Coral Reefs 27:697-705. doi: 10.1007/s00338-008-0386-3

Willis BL, van Oppen MJH, Miller DJ, et al (2006) The Role of Hybridization in the Evolution of Reef Corals. Annu Rev Ecol Evol Syst 37:489-517. doi: 10.1146/annurev.ecolsys.37.091305.110136

Wright S (1940) Breeding structure of populations in relation to speciation. Am Nat 74:232-248 
967

968

969

970

971

972

973

974

975

976

977
Yeoh S-R, Dai C-F (2009) The production of sexual and asexual larvae within single broods of the scleractinian coral, Pocillopora damicornis. Mar Biol 157:351-359. doi: 10.1007/s00227-0091322-y

Young CN, Schopmeyer SA, Lirman D (2012) A review of reef restoration and coral propagation using the threatened genus Acropora in the Caribbean and Western Atlantic. Bull Mar Sci 88:10751098. doi: $10.5343 /$ bms.2011.1143

Zubillaga AL, Márquez LM, Cróquer A, Bastidas C (2008) Ecological and genetic data indicate recovery of the endangered coral Acropora palmata in Los Roques, Southern Caribbean. Coral Reefs 27:63-72. doi: 10.1007/s00338-007-0291-1 


\section{Figure captions}

979 Figure 1 Studied area and location of the 36 studied Acropora palmata stands (black dots). A:

980 location of the Lesser Antilles within the Caribbean Sea, B: sampling locations in the Lesser

981 Antilles, C: sampling locations in Guadeloupe Island

982

983

984

985

986

987

988

989

990

991

992

993

994

995

996

997

998

999

1000

1001

1002

Figure 2 Correspondence analysis representing individual Acropora colonies based on their genotypes obtained from the analysis of 14 microsatellite loci. Grey circles represent colonies morphologically identified as A. prolifera (Japaud et al. 2014), grey squares show colonies with percentage of membership to A. palmata cluster of less than $73 \%$ and grey triangles show three additional colonies removed based on their close vicinity to A. prolifera MLGs on the correspondence analysis. Black circles represent A. cervicornis and white circles A. palmata colonies kept for all analyses.

Figure 3 Sexual dynamics of 36 sampled Acropora palmata stands in the Lesser Antilles, analysed using 14 microsatellite loci and derived from their clonal structure, based on the combination of genotypic evenness $\left(\mathrm{G}_{\mathrm{O}} / \mathrm{Ng}\right)$ and genotypic diversity $\left(\mathrm{G}_{\mathrm{O}} / \mathrm{G}_{\mathrm{E}}\right)$. Stands are divided as in Baums et al. (2006a) into four categories ranging from asexual to sexual to facilitate further discussion

Figure 4 Relationship between genetic $\left(F_{\mathrm{ST}} / 1-F_{\mathrm{ST}}\right)$ and geographic (in km) distances estimated among Acropora palmata sampling sites in the Lesser Antilles. A: all sampling sites (34 sites), B: only sampling sites with $\mathrm{N}>10$ (27 sites), C: only sampled sites with $\mathrm{N}>20$ (11 sites), D: among islands (i.e. pooling sampled sites per island).

Figure 5 Principal Coordinates Analysis (PCoA) based on genetic similarities among sampled island populations of Acropora palmata, estimated through the analysis of 13 microsatellite loci

Figure 6 Spatial autocorrelogram based on Loiselle's kinship coefficient estimated over all microsatellite loci but Apal1490, among all sampled Acropora palmata colonies. Solid line = observed values, Dotted lines = upper and lower limits of the 95\% confidence interval of 

1004 distance classes

1005 


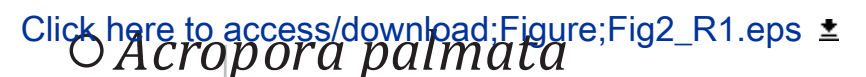

- Acropora cervicornis - Acropora prolifera $\square$ Acropora prolifera $\triangle$ Acropora prolifera

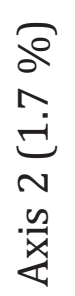

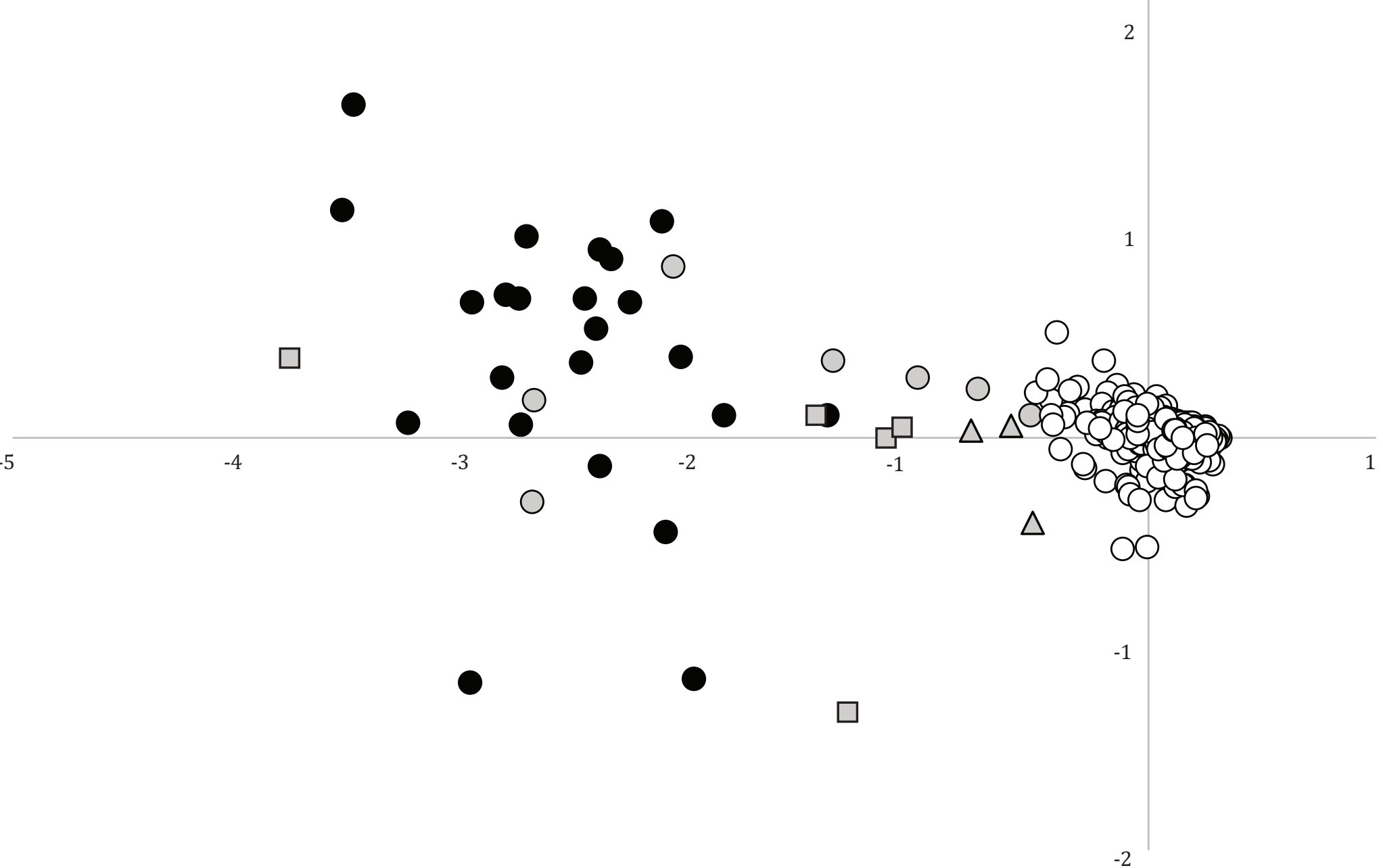

Axis 1 (3.21\%) 


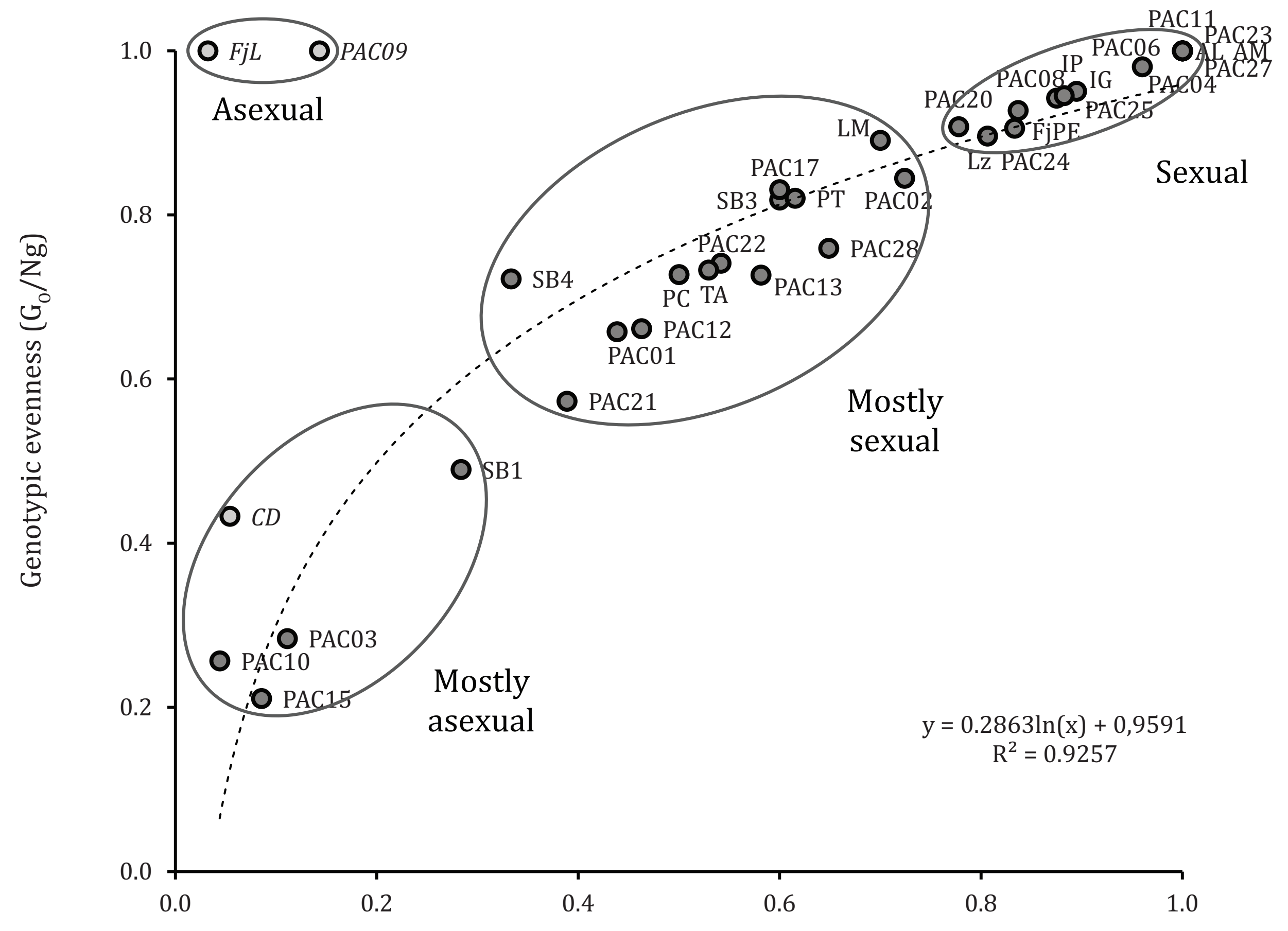

Genotypic diversity $\left(G_{0} / G_{E}\right)$ 
St. Barthélemy

- St. Martin

- Saba

0.2

- Les Saintes

- Antigua

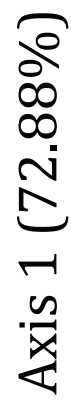

- Guadeloupe

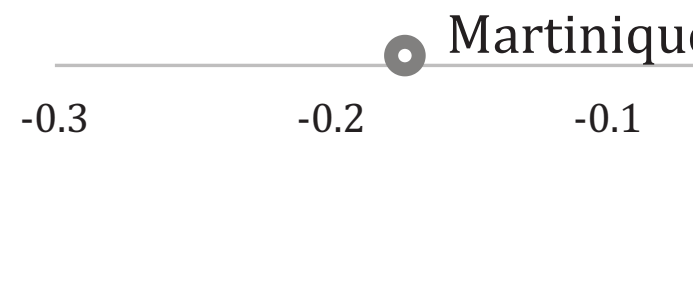

- St. Lucia

$-0.2$

$-0.1$

0.1

$-1$

0.0

0.1

0.2

- Bequia

$-0.3$

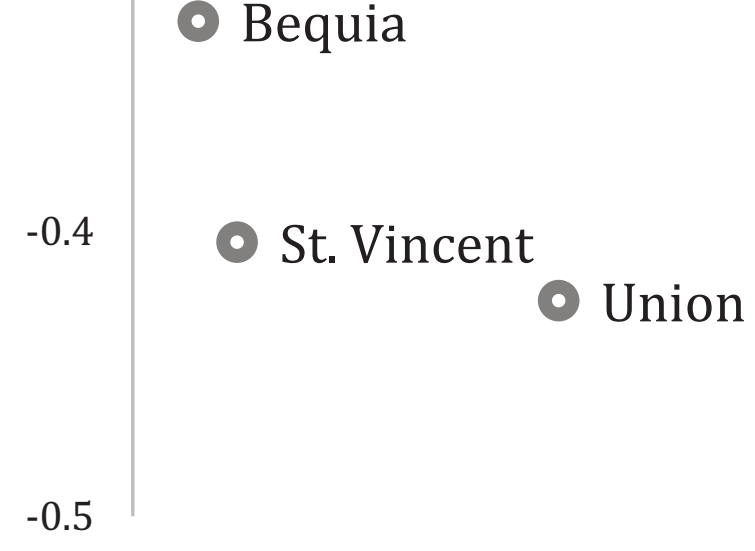




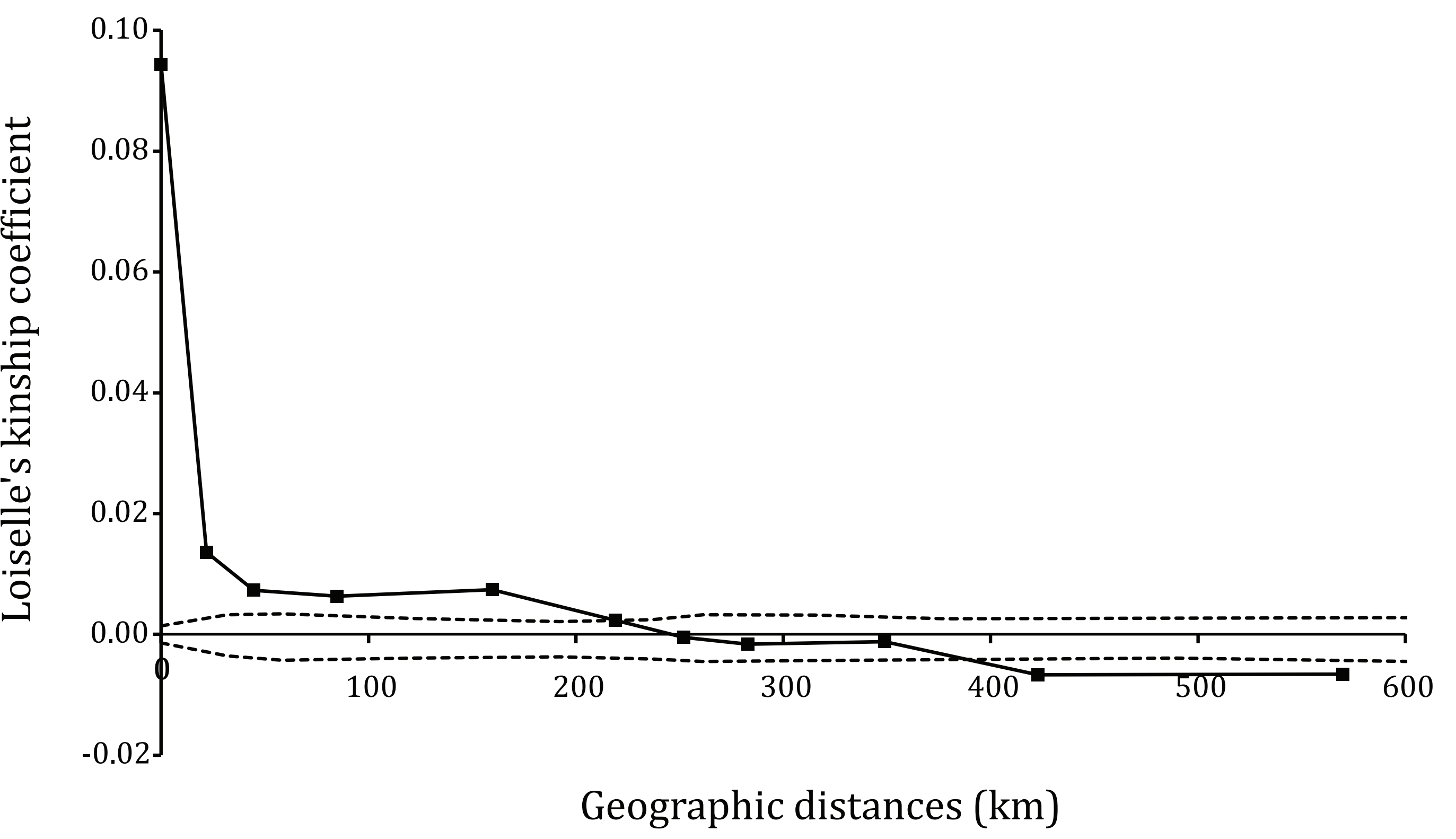


Table 1 Genetic diversity estimates in Acropora palmata stands sampled in the Lesser Antilles. $N$, Number of sampled colonies; $N g$, Number of distinct multilocus genotypes (MLG); $N g / N$, Genotypic richness; $\mathrm{G}_{0}$, Observed genotypic diversity; $G_{0} / G_{E}$, Genotypic diversity with $G_{E}$, the expected genotypic diversity; $G_{O} / \mathrm{Ng}$, Genotypic evenness; Cat, category in which each reef was classified based on the combination of $N g / N$ and $G_{O} / G_{E}$ values: asexual (1), mostly asexual (2), mostly sexual (3), and sexual (4) (from Baums et al. 2006a) ; $\mathrm{H}_{0}$, observed heterozygosity, $\mathrm{H}_{\mathrm{E}}$, unbiased expected heterozygosity; $F_{\mathrm{IS}}$, inbreeding coefficient; AR: Allelic Richness.

\begin{tabular}{|c|c|c|c|c|c|c|c|c|c|c|c|c|c|c|}
\hline Island and Site & Code & Latitude (N) & Longitude (W) & $N$ & $\mathrm{Ng}$ & $N g / N$ & Go & $G_{o} / G_{E}$ & $G_{o} / N g$ & Cat & Ho & $\mathrm{H}_{\mathrm{E}}$ & $F_{\text {IS }}$ & AR \\
\hline St. Martin & SM & & & 102 & 97 & $0.97 \pm 0.02$ & $30.58 \pm 13.35$ & $0.93 \pm 0.05$ & $0.96 \pm 0.03$ & & $0.599 \pm 0.005$ & $0.675 \pm 0.012$ & $0.119 \pm 0.031$ & $115.9 \pm 6.6$ \\
\hline Île Tintamarre I & PAC23 & $18^{\circ} 06^{\prime} 34^{\prime \prime}$ & $62^{\circ} 58^{\prime} 51^{\prime \prime}$ & 4 & 4 & 1.00 & 4.00 & 1.00 & 1.00 & 4 & 0.589 & 0.694 & 0.172 & \\
\hline Île Tintamarre II & PAC24 & $18^{\circ} 07^{\prime} 33^{\prime \prime}$ & $62^{\circ} 58^{\prime} 21^{\prime \prime}$ & 50 & 46 & 0.92 & 41.67 & 0.83 & 0.91 & 4 & 0.608 & 0.652 & 0.067 & \\
\hline Trou David & PAC25 & $18^{\circ} 04^{\prime} 24^{\prime \prime}$ & $63^{\circ} 07^{\prime} 09^{\prime \prime}$ & 48 & 47 & 0.98 & 46.08 & 0.96 & 0.98 & 4 & 0.601 & 0.680 & 0.119 & \\
\hline St. Barthélemy & SB & & & 47 & 28 & $0.59 \pm 0.08$ & $6.24 \pm 1.41$ & $0.41 \pm 0.1$ & $0.68 \pm 0.1$ & & $0.606 \pm 0.008$ & $0.693 \pm 0.004$ & $0.115 \pm 0.011$ & $126.2 \pm 18.4$ \\
\hline Anse de Grand Cul-de-Sac & SB1 & $17^{\circ} 54^{\prime} 46^{\prime \prime}$ & $62^{\circ} 47^{\prime} 59^{\prime \prime}$ & 19 & 11 & 0.58 & 5.39 & 0.28 & 0.49 & 2 & 0.615 & 0.696 & 0.107 & \\
\hline Îlet Frégate & SB3 & $17^{\circ} 56^{\prime} 22^{\prime \prime}$ & $62^{\circ} 49^{\prime} 55^{\prime \prime}$ & 15 & 11 & 0.73 & 9.00 & 0.60 & 0.82 & 3 & 0.590 & 0.698 & 0.137 & \\
\hline Pointe Milou & SB4 & $17^{\circ} 54^{\prime} 50^{\prime \prime}$ & $62^{\circ} 49^{\prime} 04^{\prime \prime}$ & 13 & 6 & 0.46 & 4.33 & 0.33 & 0.72 & 3 & 0.613 & 0.684 & 0.101 & \\
\hline Saba & Sa & & & & & & & & & & & & & 129.5 \\
\hline Southeast coast & PAC27 & $17^{\circ} 37^{\prime} 04^{\prime \prime}$ & $63^{\circ} 13^{\prime} 35^{\prime \prime}$ & 39 & 39 & 1.00 & 39.00 & 1.00 & 1.00 & 4 & 0.621 & 0.720 & 0.131 & \\
\hline Antigua & An & & & 61 & 44 & $0.76 \pm 0.05$ & $10.14 \pm 2.52$ & $0.57 \pm 0.12$ & $0.74 \pm 0.1$ & & $0.601 \pm 0.026$ & $0.667 \pm 0.014$ & $0.102 \pm 0.026$ & $102.1 \pm 8.6$ \\
\hline Nanton Point & PAC20 & $16^{\circ} 59^{\prime} 52^{\prime \prime}$ & $61^{\circ} 45^{\prime} 37^{\prime \prime}$ & 7 & 6 & 0.86 & 5.44 & 0.78 & 0.91 & 4 & 0.552 & 0.640 & 0.148 & \\
\hline Five Islands & PAC21 & $17^{\circ} 04^{\prime} 53^{\prime \prime}$ & $61^{\circ} 54^{\prime} 50^{\prime \prime}$ & 28 & 19 & 0.68 & 10.89 & 0.39 & 0.57 & 3 & 0.610 & 0.680 & 0.099 & \\
\hline Shipstern Point & PAC22 & $17^{\circ} 07^{\prime} 46^{\prime \prime}$ & $61^{\circ} 53^{\prime} 31^{\prime \prime}$ & 26 & 19 & 0.73 & 14.08 & 0.54 & 0.74 & 3 & 0.642 & 0.682 & 0.058 & \\
\hline Guadeloupe & $\mathrm{Gu}$ & & & 395 & 256 & $0.79 \pm 0.08$ & $17.86 \pm 3.5$ & $0.71 \pm 0.08$ & $0.89 \pm 0.03$ & & $0.655 \pm 0.010$ & $0.692 \pm 0.012$ & $0.053 \pm 0.01$ & $137 \pm 7.4$ \\
\hline Anse à la Barque & PAC28 & $16^{\circ} 05^{\prime} 16^{\prime \prime}$ & $61^{\circ} 46^{\prime} 14^{\prime \prime}$ & 48 & 41 & 0.85 & 31.14 & 0.65 & 0.76 & 3 & 0.672 & 0.710 & 0.123 & \\
\hline Anse Laborde & $\mathrm{AL}$ & $16^{\circ} 29^{\prime} 11^{\prime \prime}$ & $61^{\circ} 29^{\prime} 50^{\prime \prime}$ & 12 & 12 & 1.00 & 12.00 & 1.00 & 1.00 & 4 & 0.687 & 0.714 & 0.044 & \\
\hline Anse Maurice & AM & $16^{\circ} 23^{\prime} 38^{\prime \prime}$ & $61^{\circ} 24^{\prime} 13^{\prime \prime}$ & 18 & 18 & 1.00 & 18.00 & 1.00 & 1.00 & 4 & 0.663 & 0.689 & 0.029 & \\
\hline Îlet Fajou I & FjL & $16^{\circ} 21^{\prime} 16^{\prime \prime}$ & $61^{\circ} 34^{\prime} 21^{\prime \prime}$ & 31 & 1 & 0.03 & 1.00 & 0.03 & 1.00 & 1 & 0.571 & 0.571 & NA & \\
\hline Îlet Fajou II & FjPE & $16^{\circ} 21^{\prime} 35^{\prime \prime}$ & $61^{\circ} 35^{\prime} 32^{\prime \prime}$ & 42 & 39 & 0.93 & 36.75 & 0.88 & 0.94 & 4 & 0.683 & 0.718 & 0.037 & \\
\hline Îlet Gosier & IG & $16^{\circ} 11^{\prime} 60^{\prime \prime}$ & $61^{\circ} 29^{\prime} 20^{\prime \prime}$ & 17 & 16 & 0.94 & 15.21 & 0.89 & 0.95 & 4 & 0.672 & 0.707 & 0.092 & \\
\hline
\end{tabular}




\begin{tabular}{|c|c|c|c|c|c|c|c|c|c|c|c|c|c|c|}
\hline Îlets de Pigeon & IP & $16^{\circ} 10^{\prime} 00^{\prime \prime}$ & $61^{\circ} 47^{\prime} 24^{\prime \prime}$ & 15 & 14 & 0.93 & 13.24 & 0.88 & 0.95 & 4 & 0.693 & 0.742 & 0.041 & \\
\hline Le Moule & LM & $16^{\circ} 20^{\prime} 05^{\prime \prime}$ & $61^{\circ} 20^{\prime} 30^{\prime \prime}$ & 14 & 11 & 0.79 & 9.80 & 0.70 & 0.89 & 3 & 0.655 & 0.690 & -0.001 & \\
\hline Pointe à Lézard & Lz & $16^{\circ} 08^{\prime} 29^{\prime \prime}$ & $61^{\circ} 46^{\prime} 47^{\prime \prime}$ & 50 & 45 & 0.90 & 40.32 & 0.81 & 0.90 & 4 & 0.603 & 0.680 & 0.052 & \\
\hline Pointe des Châteaux & PC & $16^{\circ} 15^{\prime} 00^{\prime \prime}$ & $61^{\circ} 10^{\prime} 50^{\prime \prime}$ & 16 & 11 & 0.69 & 8.00 & 0.50 & 0.73 & 3 & 0.658 & 0.718 & 0.084 & \\
\hline Îles de la Petite Terre & PT & $16^{\circ} 10^{\prime} 36^{\prime \prime}$ & $61^{\circ} 06^{\prime} 17^{\prime \prime}$ & 16 & 12 & 0.75 & 9.85 & 0.62 & 0.82 & 3 & 0.635 & 0.647 & 0.018 & \\
\hline Tête à I'Anglais & TA & $16^{\circ} 22^{\prime} 54^{\prime \prime}$ & $61^{\circ} 45^{\prime} 50^{\prime \prime}$ & 36 & 26 & 0.72 & 19.06 & 0.53 & 0.73 & 3 & 0.647 & 0.693 & 0.069 & \\
\hline Caye à Dupont* & $C D$ & $16^{\circ} 09^{\prime} 26^{\prime \prime}$ & $61^{\circ} 32^{\prime} 33^{\prime \prime}$ & 80 & 10 & 0.13 & 4.33 & 0.05 & 0.43 & 2 & 0.679 & 0.718 & 0.064 & \\
\hline Les Saintes & LS & & & & & & & & & & & & & 124 \\
\hline Pointe Zozio & PAC01 & $15^{\circ} 52^{\prime} 60^{\prime \prime}$ & $61^{\circ} 34^{\prime} 15^{\prime \prime}$ & 75 & 50 & 0.67 & 32.89 & 0.44 & 0.66 & 3 & 0.577 & 0.673 & 0.123 & \\
\hline Martinique & $\mathrm{Ma}$ & & & 70 & 53 & $0.81 \pm 0.15$ & $10.94 \pm 3.76$ & $0.71 \pm 0.21$ & $0.71 \pm 0.17$ & & $0.626 \pm 0.015$ & $0.705 \pm 0.005$ & $0.103 \pm 0.02$ & $133.7 \pm 16.8$ \\
\hline Caye de la Perle & PACO2 & $14^{\circ} 50^{\prime} 27^{\prime \prime}$ & $61^{\circ} 13^{\prime} 31^{\prime \prime}$ & 21 & 18 & 0.86 & 15.21 & 0.72 & 0.84 & 3 & 0.584 & 0.708 & 0.161 & \\
\hline Les Roches Rouges & PACO3 & $14^{\circ} 38^{\prime} 15^{\prime \prime}$ & $61^{\circ} 08^{\prime} 21^{\prime \prime}$ & 23 & 9 & 0.39 & 2.56 & 0.11 & 0.28 & 2 & 0.657 & 0.717 & 0.072 & \\
\hline îlet Ramier & PACO4 & $14^{\circ} 32^{\prime} 40^{\prime \prime}$ & $61^{\circ} 04^{\prime} 50^{\prime \prime}$ & 7 & 7 & 1.00 & 7.00 & 1.00 & 1.00 & 4 & 0.626 & 0.700 & 0.096 & \\
\hline Pointe Burgos & PAC06 & $14^{\circ} 29^{\prime} 28^{\prime \prime}$ & $61^{\circ} 05^{\prime} 20^{\prime \prime}$ & 19 & 19 & 1.00 & 19.00 & 1.00 & 1.00 & 4 & 0.638 & 0.695 & 0.084 & \\
\hline St. Lucia & $S L$ & & & 60 & 30 & $0.56 \pm 0.16$ & $7.19 \pm 3.61$ & $0.34 \pm 0.25$ & $0.52 \pm 0.31$ & & $0.599 \pm 0.007$ & $0.693 \pm 0.006$ & $0.123 \pm 0.011$ & $126.8 \pm 4.6$ \\
\hline Jambette Point & PAC15 & $13^{\circ} 51^{\prime} 39^{\prime \prime}$ & $61^{\circ} 04^{\prime} 28^{\prime \prime}$ & 42 & 17 & 0.40 & 3.59 & 0.09 & 0.21 & 2 & 0.593 & 0.699 & 0.133 & \\
\hline Pigeon Island & PAC17 & $14^{\circ} 05^{\prime} 31^{\prime \prime}$ & $60^{\circ} 58^{\prime} 05^{\prime \prime}$ & 18 & 13 & 0.72 & 10.80 & 0.60 & 0.83 & 3 & 0.606 & 0.687 & 0.112 & \\
\hline St Vincent & sv & & & 83 & 44 & $0.41 \pm 0.25$ & $12.28 \pm 11.02$ & $0.34 \pm 0.25$ & $0.73 \pm 0.24$ & & $0.553 \pm 0.031$ & $0.618 \pm 0.027$ & $0.156 \pm 0.048$ & $106.9 \pm 5.7$ \\
\hline Châteaubelair Island & PAC08 & $13^{\circ} 17^{\prime} 58^{\prime \prime}$ & $61^{\circ} 14^{\prime} 54^{\prime \prime}$ & 41 & 37 & 0.90 & 34.31 & 0.84 & 0.93 & 4 & 0.596 & 0.666 & 0.096 & \\
\hline Duvernette Island & PAC09 & $13^{\circ} 07^{\prime} 36^{\prime \prime}$ & $61^{\circ} 12^{\prime} 29^{\prime \prime}$ & 7 & 1 & 0.14 & 1.00 & 0.14 & 1.00 & 1 & 0.571 & 0.571 & NA & \\
\hline Blue Lagoon & PAC10 & $13^{\circ} 07^{\prime} 33^{\prime \prime}$ & $61^{\circ} 11^{\prime} 40^{\prime \prime}$ & 35 & 6 & 0.17 & 1.54 & 0.04 & 0.26 & 2 & 0.493 & 0.616 & 0.215 & \\
\hline Bequia & $\mathrm{Be}$ & & & 52 & 37 & $0.85 \pm 0.15$ & $12.57 \pm 10.57$ & $0.73 \pm 0.27$ & $0.83 \pm 0.17$ & & $0.663 \pm 0.051$ & $0.704 \pm 0.023$ & $0.061 \pm 0.037$ & 105.2 \\
\hline Ships Stern & PAC11 & $12^{\circ} 59^{\prime} 43^{\prime \prime}$ & $61^{\circ} 16^{\prime} 29^{\prime \prime}$ & 2 & 2 & 1.00 & 2.00 & 1.00 & 1.00 & 4 & 0.714 & 0.726 & 0.024 & \\
\hline Wash Rock & PAC12 & $13^{\circ} 00^{\prime} 44^{\prime \prime}$ & $61^{\circ} 14^{\prime} 59^{\prime \prime}$ & 50 & 35 & 0.70 & 23.15 & 0.46 & 0.66 & 3 & 0.611 & 0.681 & 0.098 & \\
\hline Union & Un & & & & & & & & & & & & & \\
\hline Rapid Point & PAC13 & $12^{\circ} 36^{\prime} 43^{\prime \prime}$ & $61^{\circ} 27^{\prime} 08^{\prime \prime}$ & 50 & 40 & 0.80 & 29.07 & 0.58 & 0.73 & 3 & 0.625 & 0.657 & 0.041 & 106.1 \\
\hline Total & & & & 1034 & 718 & $0.75 \pm 0.04$ & $16.47 \pm 2.29$ & $0.64 \pm 0.05$ & $0.79 \pm 0.04$ & & $0.624 \pm 0.008$ & $0.684 \pm 0.006$ & $0.09 \pm 0.008$ & $125.6 \pm 4.1$ \\
\hline
\end{tabular}


Table 2 Pairwise genetic (lower as pairwise- $F_{\mathrm{ST}}$ ) and geographic distance (upper, in km) matrices among islands. Pairwise- $F_{\mathrm{ST}}$ were estimated using the ENA method provided in FREENA software. Significant pairwise- $F_{\mathrm{ST}}$ are indicated in bold (the $\mathrm{H}_{0}$ hypothesis $F_{\mathrm{ST}}=0$ was rejected if the $95 \%$ confidence interval obtained through bootstrap resampling over loci did not include zero)

\begin{tabular}{|c|c|c|c|c|c|c|c|c|c|c|c|c|}
\hline & & SM & SB & Sa & An & Gu & LS & Ma & SL & SV & Be & Un \\
\hline St. Martin & SM & 0 & 31 & 53 & 175 & 257 & 292 & 440 & 514 & 573 & 597 & 634 \\
\hline St. Barthélemy & SB & 0.002 & 0 & 52 & 144 & 227 & 263 & 411 & 486 & 546 & 570 & 608 \\
\hline Saba & Sa & 0.000 & 0.001 & 0 & 165 & 235 & 264 & 408 & 479 & 535 & 557 & 592 \\
\hline Antigua & An & 0.000 & 0.006 & 0.005 & 0 & 92 & 135 & 281 & 361 & 429 & 454 & 498 \\
\hline Guadeloupe & Gu & 0.006 & 0.011 & 0.007 & 0.001 & 0 & 45 & 189 & 269 & 337 & 363 & 408 \\
\hline Les Saintes & LS & 0.005 & 0.008 & 0.004 & 0.003 & 0.000 & 0 & 149 & 227 & 294 & 319 & 364 \\
\hline Martinique & Ma & 0.015 & 0.010 & 0.010 & 0.009 & 0.008 & 0.006 & 0 & 82 & 156 & 182 & 231 \\
\hline St. Lucia & SL & 0.025 & 0.022 & 0.017 & 0.019 & 0.014 & 0.013 & 0.006 & 0 & 77 & 103 & 154 \\
\hline St. Vincent & SV & 0.033 & 0.040 & 0.030 & 0.030 & 0.024 & 0.025 & 0.018 & 0.009 & 0 & 27 & 77 \\
\hline Bequia & $\mathbf{B e}$ & 0.028 & 0.034 & 0.024 & 0.022 & 0.018 & 0.020 & 0.013 & 0.010 & 0.002 & 0 & 51 \\
\hline Union & Un & $\mathbf{0 . 0 3 7}$ & 0.045 & 0.036 & 0.032 & 0.027 & 0.031 & 0.022 & 0.019 & 0.004 & 0.008 & 0 \\
\hline
\end{tabular}


Table 3 Estimated direction of gene flow in A. palmata along the Lesser Antilles. Lower matrix: relative directional migration coefficients among islands, based on the Jost's D index $\left(D_{M}\right)$ (significant relative coefficient indicated in bold). Upper matrix: schematic representation of the relative directional migration coefficients: positive values indicate northward gene flow and are represented as $\boldsymbol{\Delta}(\mathrm{n}=36)$, negative values indicate southward gene flow and are represented as $\boldsymbol{\nabla}(\mathrm{n}=19)$

\begin{tabular}{|c|c|c|c|c|c|c|c|c|c|c|c|c|}
\hline & & SM & SB & Sa & An & Gu & LS & Ma & SL & SV & Be & Un \\
\hline St. Martin & SM & & $\nabla$ & $\nabla$ & $\boldsymbol{\Delta}$ & $\nabla$ & $\Delta$ & $\nabla$ & $\nabla$ & $\Delta$ & $\mathbf{\Delta}$ & $\boldsymbol{\Delta}$ \\
\hline St. Barthélemy & SB & -0.019 & & $\nabla$ & $\Delta$ & $\nabla$ & $\Delta$ & $\nabla$ & $\boldsymbol{\nabla}$ & $\Delta$ & $\Delta$ & $\Delta$ \\
\hline Saba & Sa & -0.163 & -0.063 & & $\Delta$ & $\Delta$ & $\Delta$ & $\nabla$ & $\boldsymbol{\nabla}$ & $\Delta$ & $\Delta$ & $\Delta$ \\
\hline Antigua & An & 0.024 & 0.039 & 0.222 & & $\boldsymbol{\nabla}$ & $\Delta$ & $\nabla$ & $\boldsymbol{\nabla}$ & $\Delta$ & $\Delta$ & $\Delta$ \\
\hline Guadeloupe & Gu & -0.194 & -0.035 & 0.011 & -0.465 & & $\Delta$ & $\Delta$ & $\boldsymbol{\nabla}$ & $\Delta$ & $\Delta$ & $\boldsymbol{\Delta}$ \\
\hline Les Saintes & LS & 0.209 & 0.006 & 0.138 & 0.102 & 0.402 & & $\boldsymbol{\nabla}$ & $\boldsymbol{\nabla}$ & $\Delta$ & $\Delta$ & $\Delta$ \\
\hline Martinique & Ma & -0.086 & -0.065 & -0.058 & -0.102 & 0.052 & -0.114 & & $\Delta$ & $\Delta$ & $\Delta$ & $\Delta$ \\
\hline St. Lucia & SL & -0.055 & -0.035 & -0.076 & -0.041 & -0.048 & -0.085 & 0.074 & & $\Delta$ & $\boldsymbol{\Delta}$ & $\boldsymbol{\Delta}$ \\
\hline St. Vincent & SV & 0.028 & 0.009 & 0.122 & 0.073 & 0.238 & 0.208 & 0.219 & 0.207 & & $\nabla$ & $\Delta$ \\
\hline Bequia & $\mathbf{B e}$ & 0.008 & 0.006 & 0.051 & 0.060 & 0.147 & 0.085 & 0.139 & 0.047 & -0.009 & & $\nabla$ \\
\hline Union & Un & 0.081 & 0.036 & 0.135 & 0.100 & 0.165 & 0.111 & 0.134 & 0.065 & 0.084 & -0.001 & \\
\hline
\end{tabular}

